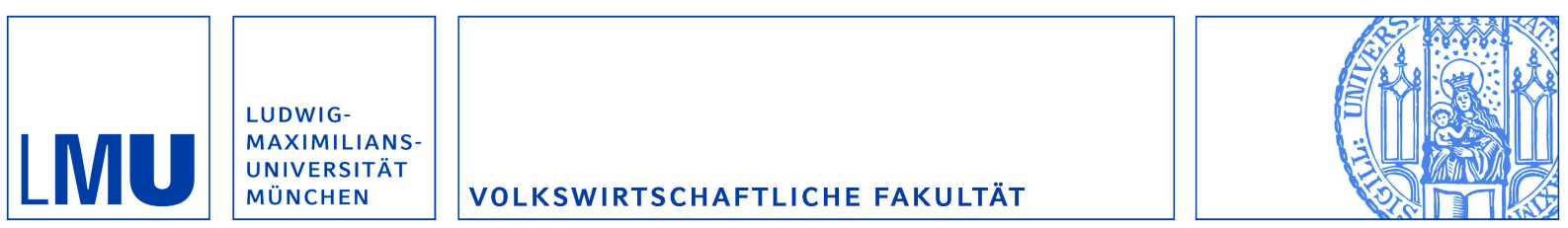

Jorzik, Nathalie und Mueller-Langer, Frank:

Multilateral Stability and Efficiency of Trade Agreements: A Network Formation Approach

Munich Discussion Paper No. 2013-3

Department of Economics

University of Munich

Volkswirtschaftliche Fakultät

Ludwig-Maximilians-Universitäł München

Online at https://doi.org/10.5282/ubm/epub. 14587 


\title{
Multilateral Stability and Efficiency of Trade Agreements: A Network Formation Approach ${ }^{0}$
}

\author{
NATHalie JorziK ${ }^{1}$ And Frank Mueller-Langer ${ }^{2}$ \\ January 18, 2013
}

\begin{abstract}
We study the endogenous network formation of bilateral and multilateral trade agreements by means of hypergraphs and introduce the equilibrium concept of multilateral stability. We consider multi-country settings with a firm in each country that produces a homogeneous good and competes as a Cournot oligopolist in each market. Under endogenous tariffs, we find that the existence of a multilateral trade agreement is always necessary for the stability of the trading system and that the formation of preferential trade agreements is always necessary for achieving global free trade. We also find that global free trade is efficient but not necessarily the only multilaterally stable trade equilibrium when countries are symmetric (heterogeneous) in terms of market size. We derive conditions under which such a conflict between overall welfare efficiency and stability occurs.
\end{abstract}

\section{Introduction}

Today, we observe a world trading system in which multilateral and bilateral trade agreements coexist. In 2010, all WTO members apart from Mongolia were members of at least one additional preferential trade agreement (PTA). According to WTO (2011), the level of participation in PTAs around the globe is increasing, particularly in the United States, the European Union and in Asian countries such as China, India and Japan. The mutual impact of PTAs and multilateral trade liberalization is a fiercely debated issue in the literature on the global trading system. ${ }^{3}$ Bagwell and Staiger $(1998,1999$ a) suggest that

\footnotetext{
${ }^{0}$ We are grateful to Jürgen Eichberger, Sylvain Béal and Hans Haller for helpful suggestions and remarks. We thank Jonas Rathfelder for excellent research assistance.

${ }^{1}$ Alfred-Weber-Institute, University of Heidelberg, Grabengasse 14, 69117 Heidelberg, Germany.

${ }^{2}$ Corresponding author: Max Planck Institute for Intellectual Property and Competition Law, Marstallplatz 1, 80539 Munich, Germany. E-mail: frank.mueller-langer@ip.mpg.de.

${ }^{3}$ The time path approach formulated by Bhagwati (1993) investigates whether regionalism leads to multilateral free trade through continued expansion of regional trading blocs. However, Baldwin (2006) and Deardorff and Stern (1997) suggest that regional and bilateral tariff reduction went hand in hand with
} 
PTAs may undermine GATT/WTO's ability to achieve an efficient multilateral trading system. Krishna (1998) shows that the formation of a PTA lowers countries' incentives for multilateral tariff reduction. In this case, PTAs act as stumbling blocks. If, however, PTA formation induces global free trade, PTAs can be seen as building blocks according to Bhagwati and Panagariya (1996). Freund (2000) suggests that multilateral trade liberalization enhances the incentives to form PTAs.

We use a network formation approach to examine the incentives of countries to form bilateral and multilateral trade agreements. We set up a three-country model with imperfect competition in which a homogeneous good is traded among the three countries. In each country there is a single domestic firm competing as a Cournot oligopolist with foreign firms. Markets in different countries are perfectly segmented. Under exogenous tariffs, we find that the formation of a multilateral trade agreement is not always necessary for the stability of the trading system. A multilateral trade agreement between heterogeneous countries in terms of market size can even destabilize the otherwise stable complete trading system that consists of bilateral trade agreements between each pair of countries. In contrast, under endogenous tariffs, we find that the formation of a multilateral trade agreement is always necessary to achieve stability. We also find that bilateral trade agreements stabilize multilateral tariff cooperation if we allow for an arbitrary number of countries. To analyze the stability of different trading systems we introduce an equilibrium concept called multilateral stability. It is an extension of the pairwise stability concept for bilateral link formation introduced by Jackson and Wolinsky (1996). The idea of multilateral stability is that players can form, as well as sever, bilateral and multilateral trade agreements. Trading systems are multilaterally stable if countries do not benefit from altering the system by single deviations. The formation of any of these agreements requires the consent of all players included, but severance can be carried out unilaterally. By extending network formation towards hypergraphs ${ }^{4}$ we are able to model the parallel formation of bilateral and multilateral trade agreements by means of links and hyperlinks, respectively. To the best of our knowledge, this paper is the first approach applying models of network formation in the theory of international trade, given that players have the opportunity to

multilateral liberalization and PTAs coexisted with multilateralism from the start. For a thorough overview on PTAs vs. multilateralism see Panagariya (2000). Recent empirical evidence provided by Karacaovali and Limão (2008) suggests that PTAs with a preferential tariff of zero slowed down multilateral trade liberalization in the European Union. See also Grossman and Helpman (1995) and Ornelas (2005).

${ }^{4}$ Durieu et al. (2005) and van den Nouweland et al. (1992) introduce network formation and communication games on a fixed hypergraph structure. 
form multilateral trade agreements as given by hypergraphs.

Goyal and Joshi (2006) were the first to analyze the formation of trade agreements as a network formation game. By assuming that countries are symmetric with respect to market size, they show that a network formation process in which players are allowed to form free-trade agreements (FTAs) leads either to a complete network or to an almost complete network. They also show that a network with one isolated country and an FTA among the remaining countries is a stable outcome. In contrast to Goyal and Joshi (2006), we find that due to country heterogeneity, a trade agreement between two countries with relatively small market size is stable but a bilateral trade agreement between two countries of different market size cannot be stable. Moreover, we show that the global trading system, defined as a multilateral trade agreement without additional bilateral trade agreements, cannot be stable whereas global free trade is stable. Furusawa and Konishi (2007) use a similar approach as Goyal and Joshi (2006) but with a differentiated product market. They show that the complete network is stable. These papers investigate whether the formation of bilateral trade agreements alone achieves global free trade. However, they refrain from posing the question of whether the formation of bilateral trade agreements lowers incentives for multilateral tariff cooperation in line with the GATT. Since we allow countries to form multilateral trade agreements in addition to bilateral trade agreements, our analysis is different from existing works on network formation of trade agreements such as Furusawa and Konishi (2007) and Goyal and Joshi (2006). We analyze the coevolution of multilateral and bilateral trade agreement formation and investigate whether bilateral trade agreements hinder or spur the process of multilateral liberalization and vice versa. The paper also shares some key elements with Saggi and Yildiz (2010, 2011), as we study the effect of bilateral trade agreements on multilateral trade liberalization in a setup where the formation of both bilateral and multilateral trade agreements is endogenous. However, there are important differences between our paper and Saggi and Yildiz (2010, 2011). Saggi and Yildiz (2010) find that global free trade is the only stable equilibrium under bilateralism and multilateralism if countries are symmetric in terms of endowment of goods. In contrast, we find that global free trade is not the unique stable trading system if countries are symmetric in terms of market size. A multilateral trade agreement together with a bilateral trade agreement can be stable if the tariff in the multilateral trade agreement is relatively large compared to market size. We derive our results from a single-model world where countries are free to simultaneously choose between bilateral and multilateral trade agreements. The hypergraph approach allows us to study the endogenous formation of 
multilateral trade agreements such as GATT also in the absence of bilateral trade agreements. This contrasts with Saggi and Yildiz (2011), where multilateral trade liberalization is achieved through bilateral trade agreements between each pair of the three countries under study. We address the conflict between the stability and efficiency of trading systems and account for political economy considerations. Saggi and Yildiz (2011, p. 356) state that "there exist circumstances where the freedom to pursue FTAs is necessary to attain global free trade", i.e. "FTAs act as strong building blocks." Our analysis allows us to confirm this effect of bilateral trade agreements under endogenous tariffs. Moreover, we are able to establish that the formation of bilateral trade agreements is always a necessary condition for achieving global free trade. Hence, we describe bilateral trade agreements as necessary building blocks. Furthermore, our endogenous tariff analysis allows us to determine the existence of a multilateral trade agreement as a necessary condition for stability. In line with the tariff complementary effect introduced by Bagwell and Staiger (1999b), we show that a country decreases the tariffs imposed on third countries as it enters more bilateral trade agreements.

The paper is organized as follows. In Section 2, we introduce the model of international trade and define a notion for stability and efficiency of hypergraph structures. Section 3 analyzes the stable and efficient trading systems under exogenously given tariffs. Section 4 generalizes the social welfare function and introduces endogenous tariffs as well as an arbitrary number of countries into the analysis. Section 5 concludes.

\section{The Model}

Following Brander and Krugman (1983) and Krishna (1998), we consider a three-country setting with $N=\{A, B, C\}$. In each country there is a firm producing a homogeneous good with marginal cost of production $c$. Each firm has the opportunity to sell in the foreign markets. ${ }^{5}$ The level of tariffs a firm faces depends on the nature of trade agreements between the domestic and the foreign country and the trading system as a whole. The collection of trade agreements between countries determines a network of trade agreements. Given this network firms choose their optimal quantities. A country can sign bilateral trade agreements (henceforth, bilateral agreements) with each of the other two countries. The whole set of countries $N$ can sign a multilateral trade agreement (henceforth, multilateral agreement). The aggregate utility in country $i$ is given by $u_{i}=q_{0}+\alpha_{i} q_{i}-\frac{1}{2} q_{i}^{2}$, where

\footnotetext{
${ }^{5}$ We assume that the re-importation of goods (parallel trade) is prohibited. See Mueller-Langer (2012) for an analysis of the ambiguous welfare effects of parallel trade freedom.
} 


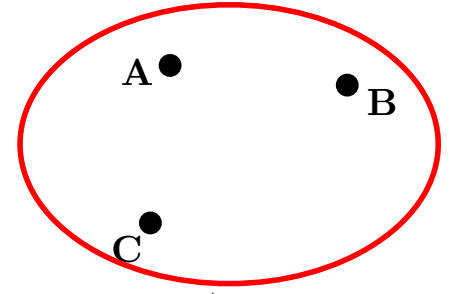

a)

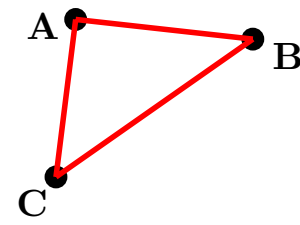

b)

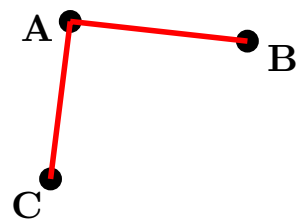

c)

Figure 1: a) Global trading system. b) Complete trading system. c) Star trading system.

$q_{0}$ denotes the consumption of the competitively produced numeraire good. With $q_{i}^{j}$ we denote the output produced by firm $j$ in country $i$ and $q_{i}=\sum_{j} q_{i}^{j}$ denotes the total sales of all firms in country $i$. The price of the good in country $i$ 's market is given by $P_{i}=\alpha_{i}-q_{i}$, where $\alpha_{i}>0$ for all $i \in N$.

\subsection{Trading Systems of Bilateral and Multilateral Agreements}

We define the notion of trading systems and introduce the structure of hypergraphs to allow the coexistence of multilateral and bilateral agreements. Let $N=\{1, \ldots, n\}$ be a finite set of countries, where $n \geq 3 . \mathcal{L}$ is a set of subsets of $N, \mathcal{L} \subseteq 2^{N}$, and is called a hypergraph on $N$. A link as a subset of countries represents a trade agreement between these countries. A hypergraph (trading system) describes the trade agreements that exist between countries in $N$. Since each country is linked with itself, we restrict our attention to trading systems $\mathcal{L}$ with $\mathcal{L} \subseteq\left\{L \in 2^{N}|| L \mid \geq 2\right\}$.

Whenever the trading system contains only one multilateral agreement that encompasses all countries with $\mathcal{L}=\{N\}$, the trading system is called global and is denoted by $\mathcal{L}^{G}$. The global trading system is illustrated in Figure 1a). The complete trading system $\mathcal{L}^{N}$ (Figure 1b)) is the family of subsets of $N$ with $\mathcal{L}^{N}=\left\{L \in 2^{N}|| L \mid=2\right\}$. It represents a trading system in which each pair of countries has a bilateral agreement. The star trading system (Figure $1 c)$ ), $\mathcal{L}_{i}^{S}$, has only bilateral agreements from the central country $i$ to each of the other countries with $\mathcal{L}_{i}^{S}=\left\{L \in 2^{N}|| L \mid=2\right.$ and $\left.i \in L\right\}$. The country which is directly linked to all other "spoke" countries is called the "hub" country. We denote the empty trading system in which no trade agreement exists by $\mathcal{L}^{e}$. Let $N_{i}(\mathcal{L})$ denote the set of countries that are directly linked with $i$ in the trading system $\mathcal{L}$ with $i \in N_{i}(\mathcal{L})$. Let $\eta_{i}(\mathcal{L})=\left|N_{i}(\mathcal{L})\right|$ denote the number of countries that have a trade agreement with $i$. One characteristic of the GATT is the famous most-favored-nation (MFN) clause. It states that 
a member country has to apply the same non-discriminatory tariff to all GATT member countries and must not discriminate against single countries. Figure 1a) illustrates the case where $A, B$ and $C$ are members of the WTO and have agreed upon common tariff reduction. A hyperlink does not allow one member to terminate trade agreements with single members within the GATT. Countries can unilaterally sever bilateral agreements.

\subsection{Social Welfare Function and Exogenous Tariffs}

We introduce the following exogenous tariff structure:

$$
t_{i}^{j}(\mathcal{L})= \begin{cases}0 & \text { if countries } i \text { and } j \text { have a bilateral agreement } \\ T & \text { if there is no trade agreement between countries } i \text { and } j \text { in } \mathcal{L} \\ t & \text { otherwise. }\end{cases}
$$

$t_{i}^{j}(\mathcal{L})$ denotes the tariff firm $j$ faces in country $i$ in $\mathcal{L}$ for each quantity supplied, whereas $T>t>0 . t$ is the tariff that countries impose when they are only linked multilaterally, i.e. if they do not participate in bilateral agreements. In this case, the same tariff applies to all member countries, as required by GATT's MFN principle. Following Saggi and Yildiz (2011), we assume that countries offer their trading partner free access to their domestic market under a bilateral agreement. This assumption is supported by GATT Article XXIV, which permits the formation of $\mathrm{PTAs}^{6}$ if tariffs are eliminated between trading partners. ${ }^{7}$ Firms maximize profits, taking other firms' outputs as given, with all firms choosing their quantities simultaneously. We assume $T>\alpha_{i} \forall i$, i.e. firms only sell abroad if at least a multilateral agreement exists. Firm $j$ 's optimization problem is:

$$
\max _{q_{i}^{j}} \pi_{i}^{j}=\left(\alpha_{i}-q_{i}\right) \cdot q_{i}^{j}-c \cdot q_{i}^{j}-t_{i}^{j}(\mathcal{L}) \cdot q_{i}^{j} .
$$

Thus the equilibrium quantity that firm $j$ supplies in country $i$ is given by:

$$
q_{i}^{j}(\mathcal{L})=\frac{\left(\alpha_{i}-c\right)}{\left(\eta_{i}(\mathcal{L})+1\right)}+\frac{\sum_{k \in N} t_{i}^{k}(\mathcal{L})}{\left(\eta_{i}(\mathcal{L})+1\right)}-t_{i}^{j}(\mathcal{L}),
$$

where $\eta_{i}(\mathcal{L})$ denotes the number of firms active in country $i$ and $k=A, B, C$. We restrict $t, 0<t<\frac{\alpha_{i}-c}{3} \forall i$, to concentrate on the case in which there is a positive quantity traded

\footnotetext{
${ }^{6}$ Henceforth, we use the term PTA for bilateral agreements when a multilateral agreement is also in place. We assume that each bilateral agreement constitutes an FTA under exogenous tariffs. We relax this assumption in our analysis of endogenous tariff formation when no multilateral trade agreement is in place.

${ }^{7}$ See Mrázová et al. (2013) for a recent analysis of the impact of Article XXIV on global welfare and its composition effect on customs union formation.
} 
between two countries that share a multilateral agreement. Firm $j$ 's profit in country $i$ with $j \in N_{i}(\mathcal{L})$ can be calculated as $\pi_{i}^{j}(\mathcal{L})=q_{i}^{j}(\mathcal{L})^{2}$. Governments maximize social welfare when they decide on tariffs and membership in trade agreements:

$$
Y_{i}(\mathcal{L})=\frac{1}{2} q_{i}{ }^{2}(\mathcal{L})+\left[\left(P_{i}(\mathcal{L})-c\right) q_{i}^{i}(\mathcal{L})+\sum_{j \neq i}\left(P_{j}(\mathcal{L})-c-t_{j}^{i}(\mathcal{L})\right) q_{j}^{i}(\mathcal{L})\right]+\sum_{j \neq i} t_{i}^{j}(\mathcal{L}) q_{i}^{j}(\mathcal{L}) .
$$

The first term represents consumer surplus in country $i$. The term in brackets contains firm $i$ 's profits in its home market and in the foreign markets, respectively. The last term is country $i$ 's tariff revenue. Total profit of firm $j$ is given by:

$$
\Pi^{j}=\sum_{i=1}^{n} \pi_{i}^{j}=\sum_{i=1}^{n}\left[\frac{\left(\alpha_{i}-c\right)}{\left(\eta_{i}(\mathcal{L})+1\right)}+\frac{\sum_{k} t_{i}^{k}(\mathcal{L})}{\left(\eta_{i}(\mathcal{L})+1\right)}-t_{i}^{j}(\mathcal{L})\right]^{2} .
$$

Since countries only supply abroad when a trade agreement exists, the social welfare function is reduced to:

$$
Y_{i}(\mathcal{L})=\frac{1}{2} q_{i}{ }^{2}(\mathcal{L})+\sum_{j \in N_{i}(\mathcal{L})}\left(\alpha_{j}-c-q_{j}(\mathcal{L})-t_{j}^{i}(\mathcal{L})\right) \cdot q_{j}^{i}(\mathcal{L})+\sum_{j \in N_{i}(\mathcal{L})} t_{i}^{j}(\mathcal{L}) \cdot q_{i}^{j}(\mathcal{L}) .
$$

\subsection{Stability and Efficiency of Trading Systems}

Countries strategically sign and sever trade agreements. Each pair of countries can sign a bilateral agreement and all countries together a multilateral agreement. In order to analyze the stability of different trading systems and to determine the shape of stable trading systems we define an equilibrium concept that selects the trading systems that are resistant to individual countries' deviations. It is an extension of the pairwise stability concept introduced by Jackson and Wolinsky (1996). We introduce the following notations:

- For $L \notin \mathcal{L}, \mathcal{L} \cup\{L\}$ is the trading system we obtain from $\mathcal{L}$ when we form the trade agreement $L$.

- For $L \in \mathcal{L}, \mathcal{L} \backslash\{L\}$ is the trading system we obtain from $\mathcal{L}$ when we sever the trade agreement $L$, if $L \in \mathcal{L}$.

Formation of a trade agreement requires the consent of all countries involved. Severance can be carried out unilaterally. A trading system $\mathcal{L}$ on $N$ is multilaterally stable if

$$
\begin{aligned}
\text { Condition }(i) & Y_{i}(\mathcal{L}) \geq Y_{i}(\mathcal{L} \backslash\{L\}) \forall L \in \mathcal{L}, \quad \forall i \in L \text { and } \\
\text { Condition }(\text { ii }) & Y_{i}(\mathcal{L} \cup\{L\})>Y_{i}(\mathcal{L}) \Rightarrow \exists j \in L, \\
& \text { such that } Y_{j}(\mathcal{L} \cup\{L\})<Y_{j}(\mathcal{L}) \quad \forall L \notin \mathcal{L} \text { hold. }
\end{aligned}
$$


This definition describes a situation in which no country has an incentive to sever any of its trade agreements and no subset of countries has an incentive to form an additional agreement. It allows the formation of multilateral agreements. For a given trading system $\mathcal{L}$, countries base their decision of whether to form or sever trade agreements on their level of social welfare. In order to analyze the efficiency of different trading systems, we consider global welfare as given by the sum of all countries' payoffs. It represents the total value generated from $\mathcal{L}$. A trading system $\mathcal{L}^{*}$ is efficient if $v(\mathcal{L})=\sum_{i \in N} Y_{i}(\mathcal{L}) \leq$ $\sum_{i \in N} Y_{i}\left(\mathcal{L}^{*}\right)=v\left(\mathcal{L}^{*}\right) \forall \mathcal{L}$.

\section{Multilateral Stability and Market Size Asymmetries}

We assume asymmetry with respect to countries' market size, which is expressed by different values of the parameter $\alpha_{i}$. We address the question of how the variation of market size across countries affects the incentives for establishing trade agreements and the stability of different trading systems. First, we analyze the symmetric case as a benchmark.

\subsection{The Symmetric Model}

We investigate possible stable trading systems with $\alpha_{A}=\alpha_{B}=\alpha_{C}=\alpha$. In contrast to Goyal and Joshi (2006), who show that in the context of bilateral link formation free trade is the unique stable outcome, we find that when countries can form bilateral and multilateral agreements, global free trade is no longer the unique stable outcome:

Proposition 1. (i) Global free trade is stable. (ii)A multilateral agreement together with one bilateral agreement is stable if $t$ is relatively large compared to the market size.

We provide all proofs in Appendix B. However, straightforward proofs are omitted. Under exogenous tariffs, global free trade is achieved under both, a complete trading system as well as a trading system that consists of a complete trading system and a multilateral agreement. $(i)$ Intuitively, no country has an incentive to sever any of its bilateral agreements under global free trade. Severance of a bilateral agreement reduces consumer surplus as the prices increase due to lower competition in the market. The domestic firm's profit in the foreign market decreases as it supplies smaller amounts due to an increase in tariffs. Tariff revenue increases from the severance of a bilateral agreement. In addition, the domestic firm's profit in its home market increases due to lower competition. In total, the additional profit in the domestic market and the additional tariff revenue cannot compensate for the loss in consumer surplus and profit in the foreign market. Hence, no 
country has an incentive to sever any of its bilateral agreements.

(ii) A multilateral agreement with an additional bilateral agreement, $\mathcal{L}=\{N,\{i, j\}\}$, can be stable for certain parameter constellations, i.e. $\frac{6}{19}(\alpha-c)<t$. This is always fulfilled whenever $t$ is relatively large compared to the market size. Intuitively, for large values of $t$, country $k$ 's tariff revenue in $\mathcal{L}=\{N,\{i, j\}\}$ is very high such that additional gains in profit due to the improved access in $i$ in $\mathcal{L} \cup\{\{i, k\}\}$ cannot compensate for the loss in tariff revenue. In this case, $k$ does not have an incentive to form a bilateral agreement. In contrast, $k$ always has an incentive to form a bilateral agreement with either $i$ or $j$ in a trading system with a bilateral agreement between $i$ and $j$ but without a multilateral agreement. Notably, the emergence of the multilateral agreement reduces $k$ 's incentive to form a bilateral agreement and is necessary for stability.

The star trading system cannot be stable since the two spoke countries have an incentive to link to each other. The empty trading system cannot be stable since a pair of countries always gains from forming a bilateral agreement.

\subsection{Two Small Countries and One Large Country}

We assume $\alpha_{A}>\alpha_{B}=\alpha_{C}=\alpha$, which implies that (country) A's market size is relatively large compared to $B$ 's and $C$ 's market size. We obtain:

Lemma 1. The global trading system cannot be stable.

This result supports the observation that countries tend to form PTAs in addition to a multilateral agreement. Intuitively, $B$ and $C$ will both gain from an additional bilateral agreement between them. Consumer surplus in both countries increases due to increased competition and lower prices. The profit of $B$ 's firm in $C$ increases and vice versa. However, there is a small negative effect on countries' welfare, since the domestic firm's profit in its home market decreases. In addition, tariff revenue decreases. As the two positive effects exceed the two negative effects, the overall welfare effect of an additional bilateral agreement is positive in both countries. Thus $B$ and $C$ will deviate and the global trading system cannot be stable. The next result provides a full description of possible stable trading systems that Figure 2 illustrates.

Proposition 2. We obtain three possible stable trading systems for $t<\frac{\alpha-c}{3}$ :

(i) For all parameter values, global free trade is a stable outcome [Figure 2a)].

(ii)Under certain conditions, a bilateral agreement between $B$ and $C$ is stable [Fig. 2b)].

(iii)Under certain conditions, a multilateral agreement with a bilateral agreement between $B$ and $C$ can be stable [Fig. 2c)]. 


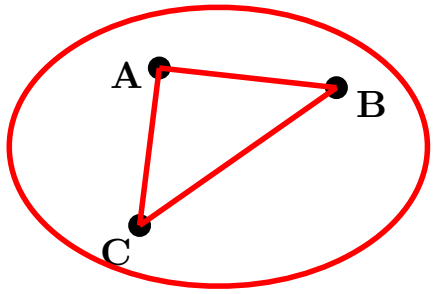

a)

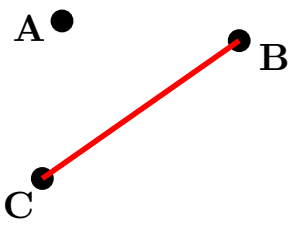

b)

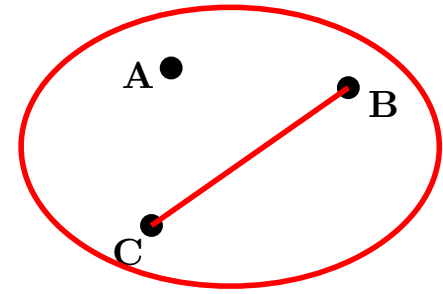

c)

Figure 2: Stable Trading Systems. a) Complete trading system with a multilateral agreement (global free trade), $b$ ) bilateral agreement between $B$ and $C$ and $c$ ) multilateral agreement with a bilateral agreement between $B$ and $C$.

There are three direct effects at work when two countries sign a bilateral agreement. First, the domestic firm faces fiercer competition from a foreign firm in the domestic market. Second, the domestic firm gains improved access to the foreign market. Third, domestic consumers benefit from greater competition in terms of lower prices. Therefore, the empty and the global trading system cannot be stable since $B$ and $C$ will form a bilateral agreement. The welfare effect from a bilateral agreement is positive in both countries. The conditions stated in Proposition 2 are given by $(i i) 2\left(\alpha_{A}-c\right)^{2}>3(\alpha-c)^{2}$ and $12\left(\alpha_{A}-c\right) t+4(\alpha-c)^{2}+16 t^{2}<24(\alpha-c) t+\left(\alpha_{A}-c\right)^{2}$ and $(i i i) 12\left(\alpha_{A}-c\right) t+4(\alpha-$ $c)^{2}+16 t^{2}>24(\alpha-c) t+\left(\alpha_{A}-c\right)^{2}$, respectively. Hence, a threshold exists for which $A$ will deviate from the trading system described in Figure $2 c$ ). To understand $A$ 's linking decision we start with a global trading system in which $A$ 's firm earns $\left(\frac{\alpha-c}{4}-\frac{t}{2}\right)^{2}$ from its operations in $B$ or $C$, respectively. Since $B$ and $C$ increase domestic welfare by forming a bilateral agreement, the profit of $A$ 's firm reduces to $\left(\frac{\alpha-c}{4}-\frac{3 \cdot t}{4}\right)^{2}$ in $B$ and $C$, respectively. Thus, the foreign markets become less attractive to $A$ 's firm. As a consequence, $A$ has an incentive to sever the multilateral agreement with $B$ and $C$ if its welfare effect is positive. This is the case for $12\left(a_{A}-c\right) t+4(a-c)^{2}+16 t^{2}<24(a-c) t+\left(a_{A}-c\right)^{2}$. In this case, a bilateral agreement between $B$ and $C$ is stable if $A$ has no incentive to form an additional bilateral agreement with $B$ or $C$. This is the case as long as $2\left(\alpha_{A}-c\right)^{2}>3(\alpha-c)^{2}$.

\subsection{One Small Country and Two Large Countries}

Assume $\alpha_{A}<\alpha_{B}=\alpha_{C}=\alpha$. In contrast to Proposition 2, we obtain:

Lemma 2. (i) A bilateral agreement between $B$ and $C$ cannot be stable. (ii) The multilateral agreement together with a bilateral agreement between $B$ and $C$ cannot be stable. 
To get an idea of the result, consider a bilateral agreement between $B$ and $C$. Intuitively, $A$ and $B$ may have an incentive to deviate by forming an additional bilateral agreement. As $B$ would be the hub country, this seems plausible, but why does $A$ benefit? Due to increased competition, consumer surplus in $A$ increases. Since $A$ 's firm obtains access to the large market in $B$, its additional profit in $B$ exceeds the profit loss in its home market. The next result characterizes the set of stable trading systems:

Proposition 3. Global free trade is the unique stable outcome.

This result differs from Proposition 2, where we obtain three possible stable trading systems. Lemma $2(i)$ already shows that a bilateral agreement between $B$ and $C$ cannot be stable anymore. The reason why a bilateral agreement between $A$ and $B$ (respectively $C$ ) is not stable is that $B$ and $C$ also have an incentive to form a bilateral agreement, since $Y_{C}\left(\mathcal{L}_{B}^{S}\right)>Y_{C}(\{\{A, B\}\})$ and $Y_{B}\left(\mathcal{L}_{B}^{S}\right)>Y_{B}(\{\{A, B\}\})$. The sum of the increase of consumer surplus in $C$ and the increase in profit of $C$ 's firm generated in $B$ exceeds the decrease in $C$ 's firm's profit in its domestic market. Hence, the overall welfare effect on $C$ is positive. A similar argument explains why a multilateral agreement together with a bilateral agreement between $A$ and $B$ is not stable either.

\subsection{Asymmetrical Case}

Assume $\alpha_{A}>\alpha_{B}>\alpha_{C}$. Consider the empty trading system. $i$ and $j$ will form a bilateral agreement if $Y_{i}\left(\mathcal{L}^{e}\right)-Y_{i}(\{\{i, j\}\})=\frac{3}{8}\left(\alpha_{i}-c\right)^{2}-\frac{1}{3}\left(\alpha_{i}-c\right)^{2}-\frac{1}{9}\left(\alpha_{j}-c\right)^{2}<0$ and $Y_{j}\left(\mathcal{L}^{e}\right)-Y_{j}(\{\{i, j\}\})=\frac{3}{8}\left(\alpha_{j}-c\right)^{2}-\frac{1}{3}\left(\alpha_{j}-c\right)^{2}-\frac{1}{9}\left(\alpha_{i}-c\right)^{2}<0$. Since $\alpha_{i} \neq \alpha_{j} \forall i \neq j$, the country with the smaller market, i.e. $j$, will always have an incentive to form a bilateral agreement, whereas $i$ only deviates if $\frac{\left(\alpha_{i}-c\right)^{2}}{24}<\frac{\left(\alpha_{j}-c\right)^{2}}{9}$. The additional profit that $i$ 's firm makes in $j$ may be too small compared to the profit loss in the home market.

We exclude a set of unstable trading systems. A bilateral agreement between $B$ and $A$ cannot be stable. The small country $C$ always has an incentive to form a bilateral agreement with a larger country, whereas the larger country always has an incentive to be the hub country in a star trading system. The same applies for a bilateral agreement between $C$ and $A$, since $B$ will have an incentive to form a trade agreement with $A$. We can further exclude any star trading system $\mathcal{L}_{i}^{S}$, because for both spoke countries we have: $Y_{j}\left(\mathcal{L}_{i}^{S}\right)-Y_{j}\left(\mathcal{L}^{N}\right)=\frac{\left(\alpha_{j}-c\right)^{2}}{3}+\frac{\left(\alpha_{i}-c\right)^{2}}{16}-\frac{11\left(\alpha_{j}-c\right)^{2}}{32}-\frac{\left(\alpha_{i}-c\right)^{2}}{16}-\frac{\left(\alpha_{k}-c\right)^{2}}{16}<0$. We obtain:

Proposition 4. (i) The complete trading system is stable. (ii) The complete trading system with a multilateral agreement is not necessarily stable. 
(i) The complete trading system is stable since, as shown above, no star trading system can be stable, and since the complete trading system with a multilateral agreement generates the same payoffs for each country. ( $i i)$ The complete trading system with a multilateral agreement is not necessarily stable, since $A$ can increase its welfare by severing its bilateral agreement with $C$. To illustrate, consider that $i$ might have an incentive to sever its bilateral agreement to any country $j$ with $\alpha_{i}>\alpha_{j}$ if $Y_{i}\left(\mathcal{L}^{G} \cup \mathcal{L}^{N}\right)-Y_{i}\left(\mathcal{L}^{G} \cup \mathcal{L}_{k}^{S}\right)<0$, which is equivalent to $2 \cdot t\left(\alpha_{i}-c\right)>4 \cdot t\left(\alpha_{j}-c\right)+t^{2}$. Therefore, we cannot guarantee its stability. Intuitively, a bilateral agreement with a smaller country may increase the profit of $i$ 's firm in the foreign market to a lesser extent than the reduction of this firm's profit in the home market. Therefore, $i$ will sever the trade agreement with $j$. Interestingly, this result $(i i)$ questions the stabilizing effect of a multilateral agreement. We will elaborate on this issue in our analysis of endogenous tariff formation.

\subsection{Efficiency of Trading Systems}

We examine the nature of the efficient trading system by analyzing global welfare of different trading systems. With $t<\frac{\alpha_{i}-c}{3} \forall \alpha_{i}$ we obtain:

Proposition 5. For any values of $\alpha_{i}$ and $c$, global free trade is an efficient outcome.

We find that overall welfare in the complete trading system and in the complete trading system with a multilateral agreement is always larger than in any arbitrary trading system. Compared to the number of stable trading systems, there are just two efficient trading systems that produce the same total output. Hence, we observe a conflict between efficiency and stability in the symmetric case and the case with two small countries and one large country. In these cases, the set of possible stable trading systems is larger than the set of efficient trading systems. However, there is no such conflict in the case with two large countries and one small country. In the case of total asymmetry, the efficient trading system can be stable.

\section{Generalizations}

We generalize the social welfare function with arbitrary weights on consumer surplus, profits and tariff revenue. We introduce endogenous tariffs and an arbitrary number of countries into the analysis. 


\subsection{Generalized Social Welfare Function}

For the symmetric model, we allow arbitrary weights on consumer surplus, firms' profit and tariff revenue and thus define a more general social welfare function from (1) with:

$$
Y_{i}(\mathcal{L})=\beta\left(\frac{1}{2} q_{i}{ }^{2}(\mathcal{L})\right)+\gamma\left(\sum_{j \in N_{i}(\mathcal{L})}\left(\alpha-c-q_{j}(\mathcal{L})-t_{j}^{i}(\mathcal{L})\right) \cdot q_{j}^{i}(\mathcal{L})\right)+\delta\left(\sum_{j \in N_{i}(\mathcal{L})} t_{i}^{j}(\mathcal{L}) \cdot q_{i}^{j}(\mathcal{L})\right)
$$

We obtain:

Proposition 6. (i) When countries place weight only on producer profit, the only stable trading systems are (a) the empty trading system and (b) the complete trading system.

(ii) When countries place weight only on consumer surplus, global free trade is stable.

(iii) When countries place weight only on tariff revenue, the only stable trading system is the global trading system.

(iv) For arbitrary values of $\beta, \gamma$ and $\delta$, the empty trading system, the global trading system and global free trade can be stable.

(i) In a political economy context, we are interested in which trading systems will emerge if welfare exclusively depends on firms' profit, i.e. $\gamma=1$ and $\beta=\delta=0$. Intuitively, the profit of $j$ 's firm in $i$ decreases with the number of firms that are active in $i$. Assume $i$ and $j$ have a bilateral agreement and $i$ forms a bilateral agreement with $k$. This reduces $j$ 's welfare since welfare is given exclusively by firm profit. The proof proceeds as follows. $(a)$ We investigate welfare under the empty trading system. The profit of $i$ 's firm is given by $\frac{(\alpha-c)^{2}}{4}$ since it only supplies in $i$. When countries only care about producer profit it can be shown that, starting from an empty trading system, no subset of countries has an incentive to form a trade agreement. The additional profit loss due to increased competition exceeds the additional profit in the foreign market. This suggests that the empty trading system is stable. (b) Under the complete trading system no country $i, i \in N$, will sever any of its trade agreements with $j, j \neq i \in N$, since the resulting decline in profits in $j$ is higher than the additional profit obtained due to lower competition in the domestic market.

(ii) Intuitively, a maximum level of competition induces lowest prices, which maximize welfare when welfare is exclusively given by consumer surplus, i.e. $\beta=1$ and $\gamma=\delta=0$.

(iii) Suppose $\delta=1$ and $\beta=\gamma=0$. Intuitively, welfare decreases with the number of bilateral agreements. The global trading system maximizes welfare, as its severance would result in the empty trading system and zero tariff revenue for each country.

(iv) This result follows directly from Propositions $6(i)-6(i i i)$. Intuitively, for high values of $\delta$, countries tend to maintain as few bilateral agreements as possible and maintain the 
multilateral agreement to maximize tariff revenue. The lower $\delta$ and the higher $\gamma$, countries prefer no agreements at all, since the additional competition will decrease firms' profit and therefore countries will sever all their agreements. For very high values of $\beta$, additional competition in the markets is profitable for consumers and therefore countries will form the complete trading system. We can further show that neither the star trading system nor the star trading system with a multilateral agreement can be stable. However, the next two examples show that a bilateral agreement and a multilateral agreement with a bilateral agreement between one pair of countries can be stable.

Example 1. Set $\beta=\frac{1}{2}, \gamma=1$ and $\delta=\frac{1}{4}$. With $(\alpha-c)=4$ and $t=1$ we get $Y_{i}(\{\{i, j\}\})=Y_{j}(\{\{i, j\}\})=\frac{16}{3}>5=Y_{i}\left(\mathcal{L}^{e}\right)=Y_{j}\left(\mathcal{L}^{e}\right)$. Furthermore, we have for country $k$ with $k \neq i \neq j$ that $Y_{k}(\{\{i, j\}\})=5>Y_{k}\left(\mathcal{L}_{i}^{S}\right)=\frac{656}{144}$ and $Y_{k}(\{\{i, j\}\})=5>$ $Y_{k}\left(\left\{\{i, j\} \cup \mathcal{L}^{G}\right\}\right)=\frac{67}{16}$ such that the conditions for multilateral stability are fulfilled.

Example 2. Set $\beta=\frac{1}{2}, \gamma=\frac{1}{2}$ and $\delta=\frac{3}{4}$. With $(\alpha-c)=4$ and $t=1$ we have $Y_{i}\left(\{\{i, j\}\} \cup \mathcal{L}^{G}\right)=Y_{j}\left(\{\{i, j\}\} \cup \mathcal{L}^{G}\right)=\frac{241}{64}>3 \frac{11}{16}=Y_{i}\left(\mathcal{L}^{G}\right)=Y_{j}\left(\mathcal{L}^{G}\right)$ and $Y_{i}(\{\{i, j\}\} \cup$ $\left.\mathcal{L}^{G}\right)=Y_{j}\left(\{\{i, j\}\} \cup \mathcal{L}^{G}\right)=\frac{241}{64}>\frac{64}{18}=Y_{i}(\{\{i, j\}\})=Y_{j}(\{\{i, j\}\})$ such that neither $i$ nor $j$ has an incentive to sever the multilateral agreement. Furthermore, we can show for $k$ with $k \neq i \neq j$ that $Y_{k}\left(\{\{i, j\}\} \cup \mathcal{L}^{G}\right)=\frac{56}{16}>Y_{k}\left(\mathcal{L}_{i}^{S} \cup \mathcal{L}^{G}\right)=3 \frac{25}{64}$ and $Y_{k}\left(\{\{i, j\}\} \cup \mathcal{L}^{G}\right)=\frac{56}{16}>$ $Y_{k}(\{\{i, j\}\})=3$. Hence, $k$ has no incentive to deviate and $\mathcal{L}=\left(\mathcal{L}^{G} \cup\{\{i, j\}\}\right)$ is stable.

\subsection{Stability of Trading Systems and Endogenous Tariffs}

We identify stable trading systems under endogenous tariffs, address the question of whether the formation of bilateral agreements hinders or facilitates multilateral tariff cooperation and discuss the role of multilateral agreements for stability. In section 3 , we considered the case of exogenously given tariffs. However, countries negotiate tariffs and, by MFN, must agree on tariff levels that apply likewise to all member states. Furthermore, as Bagwell and Staiger (1999b) show, optimal tariff choice crucially depends on the trading system. Due to the non-discrimination principle, countries choose different optimal tariffs under GATT than under an alternative trading system without MFN. In our model, the GATT agreement is represented by a multilateral agreement between all three countries. We introduce the following setting: Countries choose their optimal tariffs $t(\mathcal{L})$ that maximize domestic welfare in a trading system $\mathcal{L}$. The optimal tariff depends on the trading system and, based on the tariffs and the trading system, each country obtains a welfare level $Y_{i}(t(\mathcal{L}), \mathcal{L})$. A comparison of different welfare levels determines the set of stable trading systems. In this setting, global free trade is represented by a multilateral agreement 
in which each pair of countries has formed a PTA. We assume $\alpha_{i}=\alpha \forall i \in N$.

First, consider the case where a multilateral agreement is in place: To account for the MFN clause, we assume $t_{i}^{j}(\mathcal{L})=t_{i}^{k}(\mathcal{L})=t_{i}(\mathcal{L}), \forall j, k, \neq i$, where $t_{i}(\mathcal{L})$ is the tariff that $i$ imposes on foreign firms in the trading system $\mathcal{L}$. Following Saggi and Yildiz (2011), we assume that countries eliminate tariffs against each other when they sign additional PTAs (here, we consider FTAs) under GATT. In contrast, countries choose their non-cooperative and welfare-maximizing (potentially positive) Nash tariff level when they are not linked multilaterally. Social welfare is given by:

$$
\begin{aligned}
Y_{i}(t(\mathcal{L}), \mathcal{L}) & =\frac{1}{2}\left(\frac{n \cdot(\alpha-c)-\left(n-\tilde{\eta}_{i}(\mathcal{L})\right) \cdot t_{i}(\mathcal{L})}{(n+1)}\right)^{2}+\sum_{j \notin \tilde{N}_{i}(\mathcal{L})}\left(\frac{(\alpha-c)}{(n+1)}-\frac{\left(\tilde{\eta}_{j}(\mathcal{L})+1\right) \cdot t_{j}(\mathcal{L})}{(n+1)}\right)^{2} \\
& +\sum_{k \in \tilde{N}_{i}(\mathcal{L})}\left(\frac{\left.(\alpha-c)+\left(n-\tilde{\eta}_{k}(\mathcal{L})\right) \cdot t_{k}(\mathcal{L})\right)}{(n+1)}\right)^{2} \\
& +\left(n-\tilde{\eta}_{i}(\mathcal{L})\right) \cdot t_{i}(\mathcal{L})\left(\frac{(\alpha-c)-\left(\tilde{\eta}_{i}(\mathcal{L})+1\right) \cdot t_{i}(\mathcal{L})}{(n+1)}\right)
\end{aligned}
$$

whereas $\tilde{N}_{i}(\mathcal{L})$ denotes the number of countries that have a PTA with $i$ in the trading system $\mathcal{L},\left|\tilde{N}_{i}(\mathcal{L})\right|=\tilde{\eta}_{i}(\mathcal{L})$, with $i \in \tilde{N}_{i}(\mathcal{L})$. With $n=3$, $i$ 's optimal tariff is given by:

$$
t_{i}(\mathcal{L})=\frac{3(\alpha-c)}{\left(11 \cdot \tilde{\eta}_{i}(\mathcal{L})\right)-1} .
$$

Tariffs on third countries within the GATT decrease in the number of $i$ 's PTAs. This result is in sharp contrast to Krishna (1998), who suggests that PTAs lower countries' incentives for multilateral liberalization.

Second, consider the case when there is no multilateral agreement in place. Now, countries choose their external tariffs against countries they are bilaterally linked with noncooperatively to maximize domestic welfare. Welfare is given by:

$$
\begin{aligned}
& Y_{i}(t(\mathcal{L}), \mathcal{L})=\sum_{j \in N_{i}(\mathcal{L})} t_{i}^{j}(\mathcal{L}) \cdot\left(\frac{(\alpha-c)}{\left(\eta_{i}(\mathcal{L})+1\right)}+\frac{\sum_{k \in N_{i}(\mathcal{L})} t_{i}^{k}(\mathcal{L})}{\left(\eta_{i}(\mathcal{L})+1\right)}-t_{i}^{j}(\mathcal{L})\right) \\
& +\frac{1}{2}\left(\frac{\eta_{i}(\mathcal{L}) \cdot(\alpha-c)}{\left(\eta_{i}(\mathcal{L})+1\right)}-\frac{\sum_{k \in N_{i}(\mathcal{L})} t_{i}^{k}(\mathcal{L})}{\left(\eta_{i}(\mathcal{L})+1\right)}\right)^{2}+\sum_{j \in N_{i}(\mathcal{L})}\left(\frac{(\alpha-c)}{\left(\eta_{j}(\mathcal{L})+1\right)}+\frac{\sum_{k \in N_{j}(\mathcal{L})} t_{j}^{k}(\mathcal{L})}{\left(\eta_{j}(\mathcal{L})+1\right)}-t_{j}^{i}(\mathcal{L})\right)^{2} .
\end{aligned}
$$

We can show that, due to country symmetry, $t_{i}^{j}(\mathcal{L})=t_{i}^{k}(\mathcal{L})=t_{i}(\mathcal{L}) \forall j, k \in N_{i}(\mathcal{L}) \backslash\{i\}$ :

$$
t_{i}^{*}(\mathcal{L})=\frac{3(\alpha-c)}{7+\eta_{i}(\mathcal{L})}
$$

This implies that when $i$ 's number of bilateral trading partners increases, the tariffs levied on the foreign markets decrease also in the case where no multilateral agreement is in place. 
This tariff complementary effect was first mentioned by Bagwell and Staiger (1999b), who showed that, as the tariffs imposed on the foreign market due to an additional bilateral agreement decrease, tariffs on third parties also decrease. Next, we calculate welfare levels for different trading systems and completely characterize the nature of stable trading systems. With endogenous tariffs, stability is given by the following:

A trading system $\mathcal{L}$ on $N$ is called multilaterally stable if

(i) $Y_{i}(t(\mathcal{L}), \mathcal{L}) \geq Y_{i}(t(\mathcal{L} \backslash\{L\}), \mathcal{L} \backslash\{L\}) \forall L \in \mathcal{L}, \quad \forall i \in L$ and

(ii) $Y_{i}(t(\mathcal{L} \cup\{L\}), \mathcal{L} \cup\{L\})>Y_{i}(t(\mathcal{L}), \mathcal{L}) \Rightarrow \exists j \in L$, such that $Y_{j}(t(\mathcal{L} \cup\{L\}), \mathcal{L} \cup\{L\})<Y_{j}(t(\mathcal{L}), \mathcal{L}) \quad \forall L \notin \mathcal{L}$.

Social welfare of $i$ depends on the optimal tariff choices of all countries.

Proposition 7. (i) Global free trade is stable. (ii) Each trading system with a multilateral agreement and a PTA between one pair of countries is stable.

Proposition $7(i)$ implies that the formation of PTAs is always necessary for achieving global free trade under endogenous tariffs. We therefore claim that PTAs act as necessary building blocks under endogenous tariffs.

(ii) To investigate why the multilateral agreement with a PTA between two countries can be stable, we first calculate the resulting tariff and compare it to the tariff in the global trading system. We can show that $t_{i}\left(\mathcal{L}^{G}\right)=\frac{3(\alpha-c)}{10}>\frac{(\alpha-c)}{7}=t_{i}\left(\mathcal{L}^{G} \cup\{\{B, C\}\}\right), i=B, C$. Hence, external tariffs on $A$ decrease as $B$ and $C$ form a bilateral agreement. Next, we use this result to analyze how PTAs influence multilateral trade liberalization. By looking at the first derivative of $B$ 's welfare with respect to external tariffs,

$$
\begin{aligned}
\frac{\partial Y_{i}(t(\mathcal{L}), \mathcal{L})}{\partial t_{i}(\mathcal{L})}= & -\frac{n-\tilde{\eta}_{i}(\mathcal{L})}{n+1}\left[\frac{n(\alpha-c)-\left(n-\tilde{\eta}_{i}(\mathcal{L})\right) t_{i}(\mathcal{L})}{(n+1)}\right] \\
& +\frac{n-\tilde{\eta}_{i}(\mathcal{L})}{n+1}\left[\frac{2(\alpha-c)+2\left(n-\tilde{\eta}_{i}(\mathcal{L})\right) t_{i}(\mathcal{L})}{(n+1)}\right] \\
& +\frac{n-\tilde{\eta}_{i}(\mathcal{L})}{n+1}\left[(\alpha-c)-2\left(\tilde{\eta}_{i}(\mathcal{L})+1\right) t_{i}(\mathcal{L})\right]
\end{aligned}
$$

we can show that $B$ 's incentive to impose high external tariffs (against $A$ ) decreases in the number of PTAs. Thus, PTAs act in favor of multilateral trade liberalization. Two dominating effects drive this result, as originally brought forward by Goyal and Joshi (2006). First, as can be seen from the second line of the equation above, the positive effect of increasing external tariffs (on $A$ ) on the profit of $B$ 's firm is lower when the number of 
PTAs is higher. Second, from the third line we obtain that the positive effect of increasing external tariffs on $B$ 's tariff revenue is also lower when the number of PTAs increases. These two effects provide the intuition for the result that $B$ reduces tariffs on $A$ when $B$ signs a PTA with $C$. Hence, in the global trading system, it is more attractive for $B$ and $C$ to raise tariffs on $A$. It is less attractive for them when they form an additional PTA. These results can be used to answer the question why a trading system with a multilateral agreement and a PTA between one pair of countries is stable: Calculating the impact of a PTA between $B$ and $C$ on $A$ 's welfare, we find that due to lower external tariffs, $A$ 's welfare also increases:

$$
\begin{aligned}
& Y_{A}\left(t\left(\mathcal{L}^{G} \cup\{\{B, C\}\}\right), \mathcal{L}^{G} \cup\{\{B, C\}\}\right)-Y_{A}\left(t\left(\mathcal{L}^{G}\right), \mathcal{L}^{G}\right) \\
= & 2 \cdot\left(\frac{(\alpha-c)-\frac{3}{7}(\alpha-c)}{4}\right)^{2}-2 \cdot\left(\frac{(\alpha-c)-\frac{3}{5}(\alpha-c)}{4}\right)^{2}>0 .
\end{aligned}
$$

Due to decreasing tariffs of $B$ and $C$ on $A, A$ 's firm generates higher profits in $B$ and $C$. Thus the overall effect is positive. We also find that $B$ and $C$ benefit from forming the bilateral agreement since the free entry to the foreign market leads to an increase in both countries' payoffs. The reduction of tariffs on $A$ and the resulting increase in welfare induces $A$ to maintain its multilateral agreement with $B$ and $C$. However, forming an additional bilateral PTA with either of the two countries would reduce $A$ 's welfare.

Notably, the complete trading system cannot be stable, since all countries have an incentive to deviate and to form an additional multilateral agreement. This is the case as in a trading system that consists of a multilateral agreement and PTAs between each pair of countries, the GATT agreement reduces tariffs to zero such that all countries are better off and increase their welfare. Without the GATT agreement countries choose external tariffs non-cooperatively. This leads to a mutual reduction of welfare. Hence, the GATT stabilizes the existing trading systems and Article XXIV leads to an increase in each country's welfare.

We now analyze the efficiency of trading systems under endogenous tariffs. A trading system $\mathcal{L}^{*}$ is efficient if $v(\mathcal{L})=\sum_{i \in N} Y_{i}(t(\mathcal{L}), \mathcal{L}) \leq \sum_{i \in N} Y_{i}\left(t\left(\mathcal{L}^{*}\right), \mathcal{L}^{*}\right)=v\left(\mathcal{L}^{*}\right) \forall \mathcal{L}$.

Proposition 8. Global free trade is the unique efficient outcome.

For any trading system $\mathcal{L}$ we can calculate overall welfare under optimal tariffs $t_{i}^{j *}(\mathcal{L})$. We find that the complete trading system is no longer efficient because tariffs against foreign firms in the complete trading system, $t_{i}^{*}\left(\mathcal{L}^{N}\right)=\frac{3(\alpha-c)}{10}$, lead to a reduction of firm profits and consumer surplus. Each country's welfare in the complete trading system is 
given by $\frac{21}{50}(\alpha-c)^{2}$ whereas in the efficient trading system each country's welfare is given by $\frac{15}{32}(\alpha-c)^{2}$. With non-cooperative tariffs, countries mutually reduce their welfare level.

\subsection{Arbitrary Number of Countries}

We allow the total set of symmetric countries to form a multilateral agreement, $L=$ $\{1, \ldots, n\}$, and each pair of countries to form a bilateral agreement. We consider endogenous tariffs for an arbitrary number of countries, $n \geq 3$. We address the question of whether the complete trading system can be stable or whether a multilateral agreement is essential for stability under endogenous tariff setting (cf. Proposition 7). For $n=3$, equation (4) suggests that tariffs on third parties within a multilateral agreement decrease as the number of PTAs increases. For an arbitrary number of countries, $i$ 's optimal tariff is

$$
t_{i}(\mathcal{L})=\frac{3(\alpha-c)}{(2 n+5) \cdot \tilde{n_{i}}(\mathcal{L})-(n-2)},
$$

which suggests that the tariffs on third parties decrease if the number of $i$ 's PTAs increases. The global trading system with a single multilateral agreement that encompasses all countries is given by $\mathcal{L}^{G}=\{\{1,2, \ldots, n\}\}$. Global free trade is represented by a complete trading system together with a multilateral agreement that encompasses all countries.

Proposition 9. (i) For an arbitrary number of countries, global free trade is stable. (ii) The complete trading system is not stable. (iii) Neither the empty trading system nor (iv) the global trading system is stable.

The proof proceeds as follows. (i) We show that, starting from a complete trading system, all countries have an incentive to form a multilateral agreement. Thus, the complete trading system is not stable $[(i i)]$. (iii) The empty trading system cannot be stable since a pair of countries will deviate and increase their welfare by forming a bilateral agreement. (iv) If we consider a multilateral agreement without any PTA in place, it can be shown that countries have an incentive to form an additional PTA. Hence, a multilateral agreement without additional PTAs cannot be stable.

In the following, we focus on symmetric trading systems. This enables us to narrow the set of possible stable trading systems. We define a trading system $\mathcal{L}$ as symmetric if each country has the same number of PTAs such that $\tilde{\eta}_{i}(\mathcal{L})=\tilde{\eta}_{j}(\mathcal{L}) \forall i, j \in N$ under MFN.

Proposition 10. (i) In the class of symmetric trading systems, global free trade is the unique stable outcome. (ii) A multilateral agreement with MFN clause such as GATT is necessary for stability. 

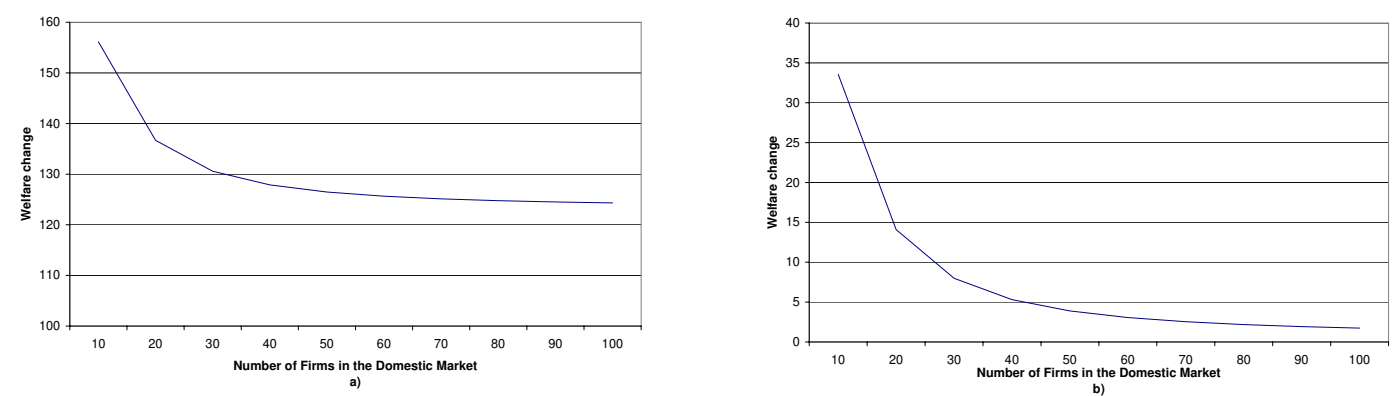

Figure 3: Welfare change from an additional bilateral agreement.

This result implies that neither the empty nor the global trading system can be stable. The proof of $(i)$ is similar to the proof of Proposition 8 in Goyal and Joshi (2006) and is omitted here. The proof of $(i i)$ shows that, without MFN, an additional bilateral agreement between $i$ and $j$ always increases welfare for both countries. Hence, we calculate $Y_{i}(t(\mathcal{L} \cup\{i, j\}), \mathcal{L} \cup\{i, j\})-Y_{i}(t(\mathcal{L}), \mathcal{L})$. We use a simulation with $n=100$ and $(\alpha-c)=100$. The results are plotted in Figure 3 . The simulation suggests that a bilateral agreement is always beneficial for all values of $\eta_{i}(\mathcal{L})$. Figure $3 a$ ) illustrates the change in welfare if the number of firms that are active in the foreign market before the bilateral agreement is given by $\eta_{j}(\mathcal{L})=1$. In contrast, in the simulation illustrated by Figure $3 b$ ) we set $\eta_{j}(\mathcal{L})=99$. The simulation demonstrates that the change in welfare from an additional bilateral agreement is always positive and highest when the number of active firms in the domestic and in the foreign market is very low.

\section{Conclusion}

Our three-country model of imperfect competition that we generalize for an arbitrary number of countries is inspired by the works of Furusawa and Konishi (2007), Goyal and Joshi (2006) and Saggi and Yildiz (2011). We extend the pairwise stability concept introduced by Jackson and Wolinsky (1996) to hypergraphs and introduce an equilibrium concept called multilateral stability. This approach allows us to endogenize tariffs in both bilateral and multilateral agreements. It is in this respect that we believe our analysis is different from Furusawa and Konishi (2007) and Goyal and Joshi (2006). In addition, our analysis of endogenous tariff formation allows us to confirm and generalize the strong building block 
effect of FTAs as brought forward by Saggi and Yildiz (2011) in the so-called FTA game. We find that the formation of PTAs is a necessary condition for achieving global free trade and describe PTAs as necessary building blocks.

We show that if countries are symmetric with respect to market size and tariffs are exogenously given, a complete trading system in which each pair of countries has a bilateral agreement together with a multilateral agreement is multilaterally stable. However, by introducing endogenous tariffs we find that the complete trading system cannot be stable anymore since countries choose their tariffs non-cooperatively. Our analysis suggests that a multilateral agreement, such as GATT together with its MFN clause, is necessary for the stability of the world trading system. We derive conditions under which multilaterally stable trading systems are inefficient from a social welfare perspective.

In addition, we find that the formation of a PTA may increase countries' incentives for multilateral trade liberalization. This finding stands in contrast to Krishna (1998), who finds that, in a political economy model, the formation of PTAs makes multilateral trade liberalization infeasible. The present paper introduces a framework that fits the analysis of the parallel formation of bilateral and multilateral agreements. Nevertheless, it is far from being a complete analysis of multilaterally stable trading systems. As a starting point for further research, we suggest analyzing the multilateral stability of trading systems in a differentiated product market model as in Furusawa and Konishi (2007). Second, our network formation approach could be used to analyze regional trading blocs where subsets of countries sign regional agreements in addition to bilateral agreements. Finally, the introduction of the WTO's Generalized Systems of Preferences (GSPs) in network formation games appears to be an interesting path for further research as this topic is relatively underdeveloped in the theoretic literature of international trade. Most of the theoretic literature assumes that member countries of a multilateral agreement, i.e. WTO member countries, have to eliminate tariffs under a bilateral agreement. The framework laid out in the present paper, however, may allow us to analyze GSPs in the sense that WTO member countries can non-cooperatively choose positive tariffs within bilateral agreements if their trading partner's market size (and, possibly, their economic development) is below a certain threshold. 


\section{A Appendix}

The welfare levels of countries $i, j, k \in\{A, B, C\}$ with $i \neq j \neq k$ under different trading systems are given by:

The empty trading system

$Y_{i}\left(\mathcal{L}^{e}\right)=\frac{3\left(\alpha_{i}-c\right)^{2}}{8}, \quad Y_{j}\left(\mathcal{L}^{e}\right)=\frac{3\left(\alpha_{j}-c\right)^{2}}{8}, \quad Y_{k}\left(\mathcal{L}^{e}\right)=\frac{3\left(\alpha_{k}-c\right)^{2}}{8}$.

The star trading system with hub country $i$

$Y_{i}\left(\mathcal{L}_{i}^{S}\right)=\frac{11\left(\alpha_{i}-c\right)^{2}}{32}+\frac{\left(\alpha_{j}-c\right)^{2}}{9}+\frac{\left(\alpha_{k}-c\right)^{2}}{9}, \quad Y_{j}\left(\mathcal{L}_{i}^{S}\right)=\frac{\left(\alpha_{j}-c\right)^{2}}{3}+\frac{\left(\alpha_{i}-c\right)^{2}}{16}$,

$Y_{k}\left(\mathcal{L}_{i}^{S}\right)=\frac{\left(\alpha_{k}-c\right)^{2}}{3}+\frac{\left(\alpha_{i}-c\right)^{2}}{16}$.

The global trading system

$Y_{i}\left(\mathcal{L}^{G}\right)=\frac{11\left(\alpha_{i}-c\right)^{2}}{32}+\frac{3\left(\alpha_{i}-c\right) \cdot t}{8}+\frac{\left(\alpha_{j}-c\right)^{2}}{16}+\frac{\left(\alpha_{k}-c\right)^{2}}{16}-\frac{\left(\alpha_{j}-c\right) \cdot t}{4}-\frac{\left(\alpha_{k}-c\right) \cdot t}{4}-\frac{t^{2}}{8}$.

The complete trading system

$Y_{i}\left(\mathcal{L}^{N}\right)=\frac{11\left(\alpha_{i}-c\right)^{2}}{32}+\frac{\left(\alpha_{j}-c\right)^{2}}{16}+\frac{\left(\alpha_{k}-c\right)^{2}}{16}$.

Bilateral agreement between $i$ and $j$

$Y_{i}(\{\{i, j\}\})=\frac{\left(\alpha_{i}-c\right)^{2}}{3}+\frac{\left(\alpha_{j}-c\right)^{2}}{9}, \quad Y_{j}(\{(i, j)\})=\frac{\left(\alpha_{j}-c\right)^{2}}{3}+\frac{\left(\alpha_{i}-c\right)^{2}}{9}, \quad Y_{k}(\{\{i, j\}\})=\frac{3\left(\alpha_{k}-c\right)^{2}}{8}$.

Multilateral agreement with a bilateral agreement between $i$ and $j$

$Y_{k}\left(\mathcal{L}^{G} \cup\{\{i, j\}\}\right)=\frac{\left(\alpha_{i}-c\right)^{2}}{16}+\frac{\left(\alpha_{j}-c\right)^{2}}{16}+\frac{11\left(\alpha_{k}-c\right)^{2}}{32}+\frac{3\left(\alpha_{k}-c\right) \cdot t}{8}-\frac{3\left(\alpha_{i}-c\right) \cdot t}{8}-\frac{3\left(\alpha_{j}-c\right) \cdot t}{8}+\frac{t^{2}}{2}$,

$Y_{i}\left(\mathcal{L}^{G} \cup\{\{i, j\}\}\right)=\frac{11\left(\alpha_{i}-c\right)^{2}}{32}+\frac{\left(\alpha_{j}-c\right)^{2}}{16}+\frac{\left(\alpha_{k}-c\right)^{2}}{16}+\frac{3\left(\alpha_{i}-c\right) t}{16}+\frac{4\left(\alpha_{j}-c\right) t}{32}-\frac{8\left(\alpha_{k}-c\right) t}{32}-\frac{11 t^{2}}{32}$,

$Y_{j}\left(\mathcal{L}^{G} \cup\{\{i, j\}\}\right)=\frac{11\left(\alpha_{j}-c\right)^{2}}{32}+\frac{\left(\alpha_{i}-c\right)^{2}}{16}+\frac{\left(\alpha_{k}-c\right)^{2}}{16}+\frac{3\left(\alpha_{j}-c\right) t}{16}+\frac{4\left(\alpha_{i}-c\right) t}{32}-\frac{8\left(\alpha_{k}-c\right) t}{32}-\frac{11 t^{2}}{32}$.

Multilateral agreement with a star trading system with hub country $i$

$Y_{i}\left(\mathcal{L}^{G} \cup \mathcal{L}_{i}^{S}\right)=\frac{\left(\alpha_{j}-c\right)^{2}}{16}+\frac{\left(\alpha_{k}-c\right)^{2}}{16}+\frac{11\left(\alpha_{i}-c\right)^{2}}{32}+\frac{2\left(\alpha_{j}-c\right) \cdot t}{16}+\frac{2\left(\alpha_{k}-c\right) \cdot t}{16}+\frac{4 \cdot t^{2}}{32}$,

$Y_{j}\left(\mathcal{L}^{G} \cup \mathcal{L}_{i}^{S}\right)=\frac{11\left(\alpha_{j}-c\right)^{2}}{32}+\frac{\left(\alpha_{i}-c\right)^{2}}{16}+\frac{\left(\alpha_{k}-c\right)^{2}}{16}+\frac{6\left(\alpha_{j}-c\right) \cdot t}{32}-\frac{3\left(\alpha_{k}-c\right) \cdot t}{8}-\frac{3 \cdot t^{2}}{32}$,

$Y_{k}\left(\mathcal{L}^{G} \cup \mathcal{L}_{i}^{S}\right)=\frac{11\left(\alpha_{k}-c\right)^{2}}{32}+\frac{\left(\alpha_{i}-c\right)^{2}}{16}+\frac{\left(\alpha_{j}-c\right)^{2}}{16}+\frac{3\left(\alpha_{k}-c\right) \cdot t}{16}-\frac{3\left(\alpha_{j}-c\right) \cdot t}{8}-\frac{3 \cdot t^{2}}{32}$. 


\section{B Appendix}

Proof of Proposition 1. Note that in this case $\alpha_{i}=\alpha \forall i$. Countries' welfare levels are given by Appendix $A$. ( $i$ ) The empty trading system cannot be stable, since each pair of countries has an incentive to deviate and with $Y_{i}\left(\mathcal{L}^{e}\right)=\frac{3(\alpha-c)^{2}}{8}<Y_{i}(\{\{i, j\}\})=\frac{4(\alpha-c)^{2}}{9}<$ $\frac{163(\alpha-c)^{2}}{288}=Y_{i}(\{\{i, j\},\{i, k\}\})$ and with $Y_{k}(\{\{i, j\},\{i, k\}\})>Y_{k}(\{\{i, j\}\}) \forall i, j, k i \neq j \neq k$ the star trading system with hub country $i$ is formed. The complete trading system is formed since $Y_{k}(\{\{i, j\},\{i, k\}\})<Y_{k}\left(\mathcal{L}^{N}\right)=\frac{15(\alpha-c)^{2}}{32}$ and $Y_{j}(\{\{i, j\},\{i, k\}\})<Y_{j}\left(\mathcal{L}^{N}\right)=$ $\frac{15(\alpha-c)^{2}}{32}$. In the complete trading system with a multilateral agreement each country gets the same payoff as in the complete trading system. Furthermore, since no country has an incentive to sever any of its bilateral agreements this system is stable. Thus the complete trading system and the complete trading system with a multilateral agreement are stable. (ii) To show that the multilateral agreement with a bilateral agreement between $B$ and $C$ can be stable note that $A$ does not have an incentive to form an additional bilateral agreement with either $B$ or $C$ if $19 t>6(\alpha-c)$. Furthermore, for $A$ to keep the multilateral agreement requires $3(\alpha-c)^{2}+16 t^{2}>12 t(\alpha-c)$. For $B$ (respectively $C$ ) to maintain the multilateral agreement requires $7(\alpha-c)^{2}+18(\alpha-c) t>99 t^{2}$. If $19 t>6(\alpha-c)$ the two latter inequalities hold. The global trading system is not stable since at least one pair of countries is able to increase its welfare by forming a bilateral agreement.

Proof of Lemma 1. To prove that the global trading system is not stable we show $Y_{i}\left(\mathcal{L}^{G}\right)<Y_{i}\left(\mathcal{L}^{G} \cup\{\{C, B\}\}\right)$ for all $i \in\{B, C\}$. This induces $7 \cdot t<6(\alpha-c)$. Since $\frac{(\alpha-c)}{3}>t$, this equation is always fulfilled. $B$ and $C$ will deviate and form an additional bilateral agreement such that Condition(ii) of multilateral stability is not satisfied.

Proof of Proposition 2. As shown in Lemma 1, a global trading system cannot be stable. The empty trading system is not stable since, as under the global trading system, $B$ and $C$ will deviate and form a bilateral agreement with:

$$
Y_{B}\left(\mathcal{L}^{e}\right)=Y_{C}\left(\mathcal{L}^{e}\right)=\frac{3(\alpha-c)^{2}}{8}<\frac{4(\alpha-c)^{2}}{9}=Y_{B}(\{\{B, C\}\})=Y_{C}(\{\{B, C\}\}) .
$$

$A$ will not form an additional agreement with $B$ if $Y_{A}(\{\{B, C\}\})>Y_{A}(\{\{B, C\},\{A, B\}\})$ and thus $2\left(\alpha_{A}-c\right)^{2}>3(\alpha-c)^{2}$. A will not form a multilateral agreement with $C$ and $B$ if $Y_{A}(\{\{B, C\}\})>Y_{A}\left(\mathcal{L}^{G} \cup\{\{B, C\}\}\right)$ and thus $12\left(\alpha_{A}-c\right) \cdot t+4(\alpha-c)^{2}+16 \cdot t^{2}<$ $24(\alpha-c) \cdot t+\left(\alpha_{A}-c\right)^{2}$. These conditions are sufficient for stability of $\mathcal{L}=\{\{B, C\}\}$ to hold (Prop. 2(ii)). If the reverse is true, $A$ has an incentive to form the multilateral agreement. This is a necessary condition for stability of the multilateral agreement with a bilateral 
agreement between $B$ and $C$ (Prop. 2(iii)). If $A$ also has an incentive to form a bilateral agreement with $B$, i.e. $2\left(\alpha_{A}-c\right)^{2} \leq 3(\alpha-c)^{2}, A$ and $C$ will then also form a bilateral agreement and the complete trading system is reached. It is stable, since no country will have an incentive to sever any of its bilateral agreements and severance of $L=\{A, B, C\}$ will not make any of the countries better off. Since $Y_{i}\left(\mathcal{L}^{N}\right)=Y_{i}\left(\mathcal{L}^{N} \cup \mathcal{L}^{G}\right) \forall i \in N$ the complete trading system with a multilateral agreement is also stable (Prop. 2(i)).

Proof of Lemma 2. $(i)$ For a bilateral agreement between $B$ and $C$ to be stable we need the condition that $A$ and $B$ will not have an incentive to form an additional bilateral agreement. In the following we demonstrate that both countries gain from an additional bilateral agreement between them. With $\alpha_{A}<\alpha$ we can show that $Y_{A}(\{\{A, B\}\})=$ $\frac{3\left(\alpha_{A}-c\right)^{2}}{8}<\frac{\left(\alpha_{A}-c\right)^{2}}{3}+\frac{(\alpha-c)^{2}}{16}=Y_{A}(\{\{A, B\},\{B, C\}\})$ and, for $B, Y_{B}(\{\{B, C\}\})=\frac{4(\alpha-c)^{2}}{9}<$ $\frac{11(\alpha-c)^{2}}{32}+\frac{\left(\alpha_{A}-c\right)^{2}}{9}+\frac{(\alpha-c)^{2}}{9}=Y_{B}(\{\{A, B\},\{B, C\}\})$, such that $A$ and $B$ have an incentive to form an additional bilateral agreement and Condition (ii) of multilateral stability is not satisfied. (ii) For the multilateral agreement with a bilateral agreement between $B$ and $C$ to be stable, the following four conditions have to be fulfilled:

(a) $6(\alpha-c) \cdot t>15 \cdot t^{2}+12\left(\alpha_{A}-c\right) \cdot t$,

(b) $18\left(\alpha_{A}-c\right)^{2}+90(\alpha-c) \cdot t>11(\alpha-c)^{2}+72\left(\alpha_{A}-c\right) \cdot t+99 \cdot t^{2}$,

(c) $6\left(\alpha_{A}-c\right) \cdot t+19 \cdot t^{2}>12(\alpha-c) \cdot t$,

(d) $12\left(\alpha_{A}-c\right) \cdot t+4(\alpha-c)^{2}+16 \cdot t^{2}>24(\alpha-c) \cdot t+\left(\alpha_{A}-c\right)^{2}$.

From condition (a) and (c) follows $6\left(\alpha_{A}-c\right) \cdot t+19 \cdot t^{2}>12(\alpha-c) \cdot t>30 \cdot t^{2}+24\left(\alpha_{A}-c\right) \cdot t$, which results in a contradiction. Therefore, the multilateral agreement with a bilateral agreement between $B$ and $C$ cannot be stable.

Proof of Proposition 3. We start with an empty trading system, which cannot be stable since $B$ and $C$ have an incentive to deviate and form a bilateral agreement. As shown in Lemma 2 this cannot be stable either and thus an additional bilateral agreement between $B$ and $A$ is formed. A bilateral agreement between $B$ and $C$ and $B$ and $A$ cannot be stable. We show that $A$ and $C$ have an incentive to form an agreement:

$$
\begin{aligned}
& Y_{C}\left(\mathcal{L}^{N}\right)=\frac{13(\alpha-c)^{2}}{32}+\frac{\left(\alpha_{A}-c\right)^{2}}{16}>\frac{19(\alpha-c)^{2}}{48}, \\
& Y_{A}\left(\mathcal{L}^{N}\right)=\frac{11\left(\alpha_{A}-c\right)^{2}}{32}+\frac{(\alpha-c)^{2}}{8}>\frac{\left(\alpha_{A}-c\right)^{2}}{3}+\frac{(\alpha-c)^{2}}{16} .
\end{aligned}
$$


The complete trading system is formed, where $Y_{i}\left(\mathcal{L}^{N}\right)=Y_{i}\left(\mathcal{L}^{N} \cup \mathcal{L}^{G}\right) \forall i \in N$. None of the countries has an incentive to sever one of their agreements and we can thus conclude that it is stable. The global trading system cannot be stable, as shown in Lemma 1. With

$$
\begin{aligned}
& Y_{B}(\{\{A, B\}\})=\frac{(\alpha-c)^{2}}{3}+\frac{\left(\alpha_{A}-c\right)^{2}}{9}<Y_{B}\left(\mathcal{L}_{B}^{S}\right)=\frac{11(\alpha-c)^{2}}{32}+\frac{\left(\alpha_{A}-c\right)^{2}}{9}+\frac{(\alpha-c)^{2}}{9} \\
& \text { and } \left.Y_{C}(\{B, A\}\}\right)=\frac{3(\alpha-c)^{2}}{8}<Y_{C}\left(\mathcal{L}_{B}^{S}\right)=\frac{19(\alpha-c)^{2}}{48}
\end{aligned}
$$

a bilateral agreement between $B$ and $A$ (respectively $C$ and $A$ ) cannot be stable.

Proof of Proposition 4. (i) Condition (ii) of multilateral stability is trivially satisfied, since adding the multilateral agreement makes no country better off. Condition $(i)$ is also satisfied, since the severance of any of the existing agreements will result in a star trading system, where the payoff for any of the two spoke countries $i$ is given by $\frac{1}{3}\left(\alpha_{i}-c\right)^{2}+\frac{1}{16}\left(\alpha_{j}-\right.$ $c)^{2}$ with hub country $j$, which is smaller than $Y_{i}\left(\mathcal{L}^{N}\right)=\frac{11}{32}\left(\alpha_{A}-c\right)^{2}+\frac{1}{16}\left(\alpha_{j}-c\right)^{2}+\frac{1}{16}\left(\alpha_{k}-c\right)^{2}$ $\forall i \neq j \neq k$. Hence, the complete trading system is stable.

Proof of Proposition 5. From (1) we obtain that total welfare of the complete trading system is given by $\sum_{i \in N} Y_{i}\left(\mathcal{L}^{N}\right)=\sum_{i \in N} \frac{1}{2}\left(\frac{\left(\alpha_{i}-c\right) n}{n+1}\right)^{2}+\sum_{i \in N} \sum_{j \in N_{i}\left(\mathcal{L}^{N}\right)}\left(\frac{\left(\alpha_{j}-c\right)}{(n+1)}\right)^{2}$. By comparison, in an arbitrary trading system the total welfare is given by:

$$
\begin{aligned}
\sum_{i \in N} Y_{i}\left(\mathcal{L}^{N}\right)= & \sum_{i \in N}\left[\frac { 1 } { 2 } \left(\left(\frac{\left(\alpha_{i}-c\right) \eta_{i}(\mathcal{L})}{\eta_{i}(\mathcal{L})+1}\right)^{2}+\left(\sum_{j \in N_{i}(\mathcal{L})} \frac{\sum_{k \in N} t_{i}^{k}(\mathcal{L})-\left(\eta_{i}(\mathcal{L})+1\right) t_{i}^{j}(\mathcal{L})}{\eta_{i}(\mathcal{L})+1}\right)^{2}\right.\right. \\
+ & \left.\cdot \sum_{j \in N_{i}(\mathcal{L})} \frac{\left(\alpha_{i}-c\right)\left(\sum_{k \in N} t_{i}^{k}(\mathcal{L})-\left(\eta_{i}(\mathcal{L})+1\right) t_{i}^{j}(\mathcal{L})\right)}{\eta_{i}(\mathcal{L})+1}\right) \\
+ & \sum_{j \in N_{i}(\mathcal{L})}\left[\left(\frac{\left(\alpha_{j}-c\right)}{\left(\eta_{j}(\mathcal{L})+1\right)}+\frac{\sum_{k \in N} t_{j}^{k}(\mathcal{L})-\left(\eta_{j}(\mathcal{L})+1\right) t_{j}^{i}(\mathcal{L})}{\eta_{j}(\mathcal{L})+1}\right)\right. \\
& \left.\left(\frac{\left(\alpha_{j}-c\right)+\sum_{k \in N} t_{j}^{k}(\mathcal{L})-\left(\eta_{j}(\mathcal{L})+1\right) t_{j}^{i}(\mathcal{L})}{\eta_{j}(\mathcal{L})+1}\right)\right] \\
+ & \left.\sum_{j \in N_{i}(\mathcal{L})} t_{i}^{j}(\mathcal{L})\left(\frac{\left(\alpha_{i}-c\right)+\sum_{k \in N} t_{i}^{k}(\mathcal{L})-\left(\eta_{i}(\mathcal{L})+1\right) t_{i}^{j}(\mathcal{L})}{\eta_{i}(\mathcal{L})+1}\right)\right]
\end{aligned}
$$

where the first two lines represent consumer surplus, the third and fourth line firms' profit and the last line tariff revenues. With $\sum_{i \in N} \sum_{j \in N_{i}(\mathcal{L})}\left(\sum_{k \in N} t_{j}^{k}(\mathcal{L})-\left(\eta_{j}(\mathcal{L})+1\right) t_{j}^{i}(\mathcal{L})\right) \leq 0$ for an arbitrary trading system $\mathcal{L}$, we can directly see that the complete trading system maximizes total welfare when countries are linked multilaterally, as $\eta_{i}(\mathcal{L})=n \forall i$. 
Without the multilateral agreement, global welfare is given by:

$$
\begin{aligned}
\sum_{i \in N} Y_{i}(\mathcal{L}) & =\sum_{i \in N}\left[\frac{1}{2}\left(\frac{\left(\alpha_{i}-c\right) \eta_{i}(\mathcal{L})}{\eta_{i}(\mathcal{L})+1}\right)^{2}+\sum_{j \in N_{i}(\mathcal{L})}\left(\frac{\left(\alpha_{j}-c\right)}{\left(\eta_{j}(\mathcal{L})+1\right)}\right)^{2}\right] \\
& =\sum_{i \in N} \frac{\left(\alpha_{i}-c\right)^{2}\left[\eta_{i}(\mathcal{L})^{2}+2 \eta_{i}(\mathcal{L})\right]}{2\left(\eta_{i}(\mathcal{L})+1\right)^{2}} \leq \sum_{i \in N} Y_{i}\left(\mathcal{L}^{N}\right)
\end{aligned}
$$

Proof of Proposition 6. (i) We asume $\gamma=1$ and $\beta=\delta=0$ in (2). Recall that $t<\frac{(\alpha-c)}{3}$. (a) Welfare in the empty trading system is given by $Y_{i}\left(\mathcal{L}^{e}\right)=\frac{(\alpha-c)^{2}}{4}$. Addition of a bilateral agreement between any pair of countries levies $Y_{i}\left(\mathcal{L}^{e}\right)-Y_{i}(\{\{i, j\}\})=\frac{(\alpha-c)^{2}}{4}-$ $\frac{2 \cdot(\alpha-c)^{2}}{9}>0$. Hence, no bilateral agreement is formed. For the global trading system we have $Y_{i}\left(\mathcal{L}^{e}\right)-Y_{i}\left(\mathcal{L}^{G}\right)=\frac{(\alpha-c)^{2}}{4}-\frac{3 \cdot(\alpha-c)^{2}}{16}-\frac{3}{4} \cdot t^{2}+\frac{t \cdot(\alpha-c)}{4}>0$. Hence, the empty trading system is stable.(b) Now consider a star trading system with hub country $A$. $B$ and $C$ 's payoff is given by $\frac{(\alpha-c)^{2}}{16}+\frac{(\alpha-c)^{2}}{9}$. In the complete trading system each country obtains a payoff of $\frac{3 \cdot(\alpha-c)}{16}$. In the star trading system with hub country $A$ with a multilateral agreement, $B$ and $C$ 's payoffs are given by $\frac{3 \cdot(\alpha-c)^{2}}{16}+\frac{5}{8} \cdot t^{2}-\frac{t \cdot(\alpha-c)}{4}<\frac{3 \cdot(\alpha-c)^{2}}{16}$. Thus, the complete trading system with a multilateral agreement is formed. A multilateral agreement with a bilateral agreement between a pair of countries is not stable since the country without any bilateral agreement has an incentive to form a bilateral agreement with $\frac{3 \cdot(\alpha-c)^{2}}{16}+\frac{22}{16} \cdot t^{2}-\frac{t \cdot(\alpha-c)}{2}<\frac{3 \cdot(\alpha-c)^{2}}{16}+\frac{5}{8} \cdot t^{2}-\frac{t \cdot(\alpha-c)}{4}$.

(ii) For $\beta=1$ and $\gamma=\delta=0$ in (2), consider a trading system without multilateral agreement. For an arbitrary network $\mathcal{L}$, consumer surplus from an additional bilateral agreement between countries $i$ and $j$ with $\{(i, j)\} \notin \mathcal{L}$ is given by $Y_{i}(\mathcal{L} \cup\{\{i, j\}\})-Y_{i}(\mathcal{L})=$ $\frac{1}{2}\left[\frac{\left(\eta_{i}(\mathcal{L})+1\right)^{2}(\alpha-c)^{2}}{\left(\eta_{i}(\mathcal{L})+2\right)^{2}}-\frac{\left(\eta_{i}(\mathcal{L})\right)^{2}(\alpha-c)^{2}}{\left(\eta_{i}(\mathcal{L})+1\right)^{2}}\right]>0$, since $t_{i}^{j}(\mathcal{L})=T$ for any pair of countries without trade agreement and $t_{i}^{j}(\mathcal{L})=0$ with a bilateral agreement between $i$ and $j$. This implies that in the absence of a multilateral agreement an additional bilateral agreement is always profitable. Thus, countries will form as many agreements as possible. However, if a multilateral agreement is in place, social welfare is given by $Y_{i}(\mathcal{L})=\frac{1}{2}\left(\frac{n(\alpha-c)}{(n+1)}-\frac{\left(n-\tilde{\eta}_{i}(\mathcal{L})\right) \cdot t}{(n+1)}\right)^{2}$, where $\tilde{\eta}_{i}(\mathcal{L})$ denotes the number of countries that are bilaterally linked with $i$ under MFN where $i \in \tilde{\eta}_{i}(\mathcal{L})$ and $\tilde{\eta}_{i}(\mathcal{L})=\left|\tilde{N}_{i}(\mathcal{L})\right|$. The first derivative implies: $\frac{\partial Y_{i}(\mathcal{L})}{\partial \tilde{\eta}_{i}(\mathcal{L})}=$ $\left(\frac{n(\alpha-c)}{(n+1)}-\frac{\left(n-\tilde{\eta}_{i}(\mathcal{L})\right) \cdot t}{(n+1)}\right) \cdot\left(\frac{t}{n+1}\right)>0$ with $t<\frac{(\alpha-c)}{3}$. Hence, it is again attractive for countries to form as many bilateral agreements as possible under MFN.

(iii) Assume $\delta=1, \beta=\gamma=0$ in (2). Since the tariff between two countries in a bilateral agreement is zero and in a multilateral agreement is $t$, we have $Y_{i}(\mathcal{L})=\left(\eta_{i}(\mathcal{L})-\tilde{\eta}_{i}(\mathcal{L})\right) \cdot t$. $\left(\frac{\alpha-c}{\eta_{i}(\mathcal{L})+1}+\frac{\left(\eta_{i}(\mathcal{L})-\tilde{\eta}_{i}(\mathcal{L})\right) \cdot t-\left(\eta_{i}(\mathcal{L})+1\right) \cdot t}{\eta_{i}(\mathcal{L})+1}\right) \cdot \tilde{N}_{i}(\mathcal{L})$ denotes the set of countries that have a bilateral 
agreement with $i$ in addition to the multilateral agreement, with $i \in \tilde{N}_{i}(\mathcal{L})$ in the trading system $\mathcal{L}$. We observe $\frac{\partial Y_{i}(\mathcal{L})}{\partial \tilde{\eta}_{i}(\mathcal{L})}<0$ such that welfare decreases with the number of bilateral agreements. Therefore, the global trading system maximizes welfare. Its severance would result in the empty trading system and zero tariff revenue for each country.

Proof of Proposition 7. In order to calculate each country's welfare level for a given trading system we insert the optimal tariff level under GATT (equation(4)) and the optimal tariff level without GATT (equation (6)) into formula (3) and (5), respectively. With $t_{i}\left(\mathcal{L}^{N}\right)=\frac{3(\alpha-c)}{10}$ we obtain that $Y_{i}\left(t\left(\mathcal{L}^{N}\right), \mathcal{L}^{N}\right)=\frac{21}{50}(\alpha-c)^{2}$ for all $i$, whereas tariffs are zero in the multilateral agreement with a PTA between each pair of countries and $Y_{i}\left(t\left(\mathcal{L}^{G} \cup \mathcal{L}^{N}\right), \mathcal{L}^{G} \cup \mathcal{L}^{N}\right)=\frac{15}{32}(\alpha-c)^{2} \quad \forall i$, such that all countries are better off under the GATT regime (Proposition $7(i)$ ) and the complete trading system cannot be stable. Furthermore, $Y_{i}\left(t\left(\mathcal{L}^{G} \cup\{\{B, C\}\}\right), \mathcal{L}^{G} \cup\{\{B, C\}\}\right)=\frac{2199}{4900}(\alpha-c)^{2} \forall i \in\{B, C\}$ and $Y_{A}\left(t\left(\mathcal{L}^{G} \cup\{\{B, C\}\}\right), \mathcal{L}^{G} \cup\{\{B, C\}\}\right)=\frac{108}{245}(\alpha-c)^{2}$ and a PTA with $B$ will reduce $A$ 's payoff. Moreover, a single bilateral agreement between any two countries is not stable, since all countries are better off under the GATT regime with $Y_{i}(t(\{\{i, j\}\}),\{\{i, j\}\})=$ $\frac{4}{9}(\alpha-c)^{2}<\frac{2199}{4900}(\alpha-c)^{2} \forall i, j$ and $Y_{k}(t(\{\{i, j\}\}),\{\{i, j\}\})=\frac{3}{8}(\alpha-c)^{2}<\frac{108}{245}(\alpha-c)^{2}$. With $Y_{k}\left(t\left(\mathcal{L}^{G} \cup\{\{i, j\}\}\right), \mathcal{L}^{G} \cup\{\{i, j\}\}\right)=\frac{108}{245}(\alpha-c)^{2}>\frac{345}{784}(\alpha-c)^{2}=Y_{k}\left(t\left(\mathcal{L}^{G} \cup\right.\right.$ $\left.\{\{i, j\},\{j, k\}\}), \mathcal{L}^{G} \cup\{\{i, j\},\{j, k\}\}\right)$ a multilateral agreement with a PTA between $i$ and $j$ is stable (Proposition $7(i i)$ ). The empty trading system is not stable since any arbitrary pair of countries has an incentive to deviate with $Y_{i}(t(\{\{i, j\}\}),\{\{i, j\}\})=\frac{4}{9}(\alpha-c)^{2}>$ $\frac{3}{8}(\alpha-c)^{2}=Y_{i}\left(t\left(\mathcal{L}^{e}\right), \mathcal{L}^{e}\right)$.

Proof of Proposition 9. ( $i$ ) and (ii): We show that under the GATT regime each country's welfare decreases if it severs any of its PTAs. With $t_{i}^{*}\left(\mathcal{L}^{G} \cup \mathcal{L}^{N} \backslash\{\{i, j\}\}\right)=$ $t_{j}^{*}\left(\mathcal{L}^{G} \cup \mathcal{L}^{N} \backslash\{\{i, j\}\}\right)=\frac{3 \cdot(\alpha-c)}{11 \cdot(n-1))-1}$ and $n \geq 3$ we have:

$$
\begin{aligned}
& Y_{i}\left(t\left(\mathcal{L}^{G} \cup \mathcal{L}^{N}\right), \mathcal{L}^{G} \cup \mathcal{L}^{N}\right)-Y_{i}\left(t\left(\mathcal{L}^{G} \cup \mathcal{L}^{N} \backslash\{\{i, j\}\}\right), \mathcal{L}^{G} \cup \mathcal{L}^{N} \backslash\{\{i, j\}\}\right) \\
= & \frac{1}{2}\left(\frac{n(\alpha-c)}{n+1}\right)^{2}+n \cdot\left(\frac{(\alpha-c)}{n+1}\right)^{2}-\frac{1}{2}\left(\frac{n(\alpha-c)-\left(\frac{3 \cdot(\alpha-c)}{11 \cdot(n-1)-1}\right)}{n+1}\right)^{2} \\
- & \left(\frac{(\alpha-c)-((n-1)+1) \cdot\left(\frac{3 \cdot(\alpha-c)}{11 \cdot(n-1)-1}\right)}{n+1}\right)^{2}-(n-2) \cdot\left(\frac{(\alpha-c)}{n+1}\right)^{2} \\
- & \left(\frac{(\alpha-c)+\left(\frac{3 \cdot(\alpha-c)}{11 \cdot(n-1)-1}\right)}{n+1}\right)^{2}-\left(\frac{3 \cdot(\alpha-c)}{11 \cdot(n-1)-1}\right) \cdot\left(\frac{(\alpha-c)-n \cdot\left(\frac{3 \cdot(\alpha-c)}{11 \cdot(n-1)-1}\right)}{n+1}\right)>0 .
\end{aligned}
$$

This suggests that, without GATT, countries in the complete trading system have an incentive to form a multilateral agreement. The complete trading system is not stable. 
With $t_{i}^{i}=0$ and $t_{i}^{j}\left(\mathcal{L}^{N}\right)=\tilde{t} \forall j \neq i$ :

$$
\begin{aligned}
Y_{i}\left(t\left(\mathcal{L}^{N}\right), \mathcal{L}^{N}\right) & =\frac{1}{2}\left(\frac{n(\alpha-c)}{n+1}-\frac{(n-1) \cdot \tilde{t}}{n+1}\right)^{2}+(n-1) \cdot\left(\frac{(\alpha-c)}{n+1}-\frac{2 \cdot \tilde{t}}{n+1}\right)^{2} \\
& +(n-1) \cdot \tilde{t}\left(\frac{(\alpha-c)}{n+1}-\frac{2 \cdot \tilde{t}}{n+1}\right)+\left(\frac{(\alpha-c)+(n-1) \cdot \tilde{t}}{n+1}\right)^{2} .
\end{aligned}
$$

We can therefore show that

$$
Y_{i}\left(t\left(\mathcal{L}^{G} \cup \mathcal{L}^{N}\right), \mathcal{L}^{G} \cup \mathcal{L}^{N}\right)-Y_{i}\left(t\left(\mathcal{L}^{N}\right), \mathcal{L}^{N}\right)=\frac{1}{2}\left(\frac{(n-1)^{2} \cdot \tilde{t}^{2}}{(n+1)^{2}}\right)+\left(\frac{(n-1)(\alpha-c) \cdot \tilde{t}}{(n+1)^{2}}\right)>0 .
$$

(iii) The empty trading system cannot be stable since a pair of countries will deviate and increase their welfare by forming a bilateral agreement:

$$
\begin{aligned}
& Y_{i}(t(\{\{i, j\}\}),\{\{i, j\}\})-Y_{i}\left(t\left(\mathcal{L}^{e}\right), \mathcal{L}^{e}\right)=\frac{1}{2}\left(\frac{2(\alpha-c)-\frac{3}{9}(\alpha-c)}{3}\right)^{2} \\
+ & \left(\frac{(\alpha-c)+\frac{3}{9}(\alpha-c)}{3}\right)^{2}+\left(\frac{(\alpha-c)+\frac{3}{9}(\alpha-c)-(\alpha-c)}{3}\right)^{2}+\left(\frac{(\alpha-c)+\frac{3}{9}(\alpha-c)}{3}\right)^{2} \\
+ & \left(\frac{3(\alpha-c)}{9}\right)\left(\frac{(\alpha-c)+\frac{3}{9}(\alpha-c)-(\alpha-c)}{3}\right)-\frac{3}{8}(\alpha-c)^{2}>0 .
\end{aligned}
$$

Hence, these two countries can achieve a higher payoff when they form a trade agreement. (iv) If we consider a multilateral agreement with MFN clause but without any PTAs in place, countries have an incentive to form an additional PTA as $Y_{i}\left(t\left(\mathcal{L}^{G} \cup\{\{i, j\}\}\right), \mathcal{L}^{G} \cup\right.$ $\{\{i, j\}\})-Y_{i}\left(t\left(\mathcal{L}^{G}\right), \mathcal{L}^{G}\right)=3(\alpha-c)^{2} \frac{5 n+32}{(n+7)^{2}(n+4)^{2}}>0$. Hence, a multilateral agreement without additional PTAs cannot be stable.

Proof of Proposition 10. (i) In a symmetric trading system with a multilateral agreement, two countries that are not linked bilaterally improve by forming a bilateral agreement. This result can be shown similarly to the second part of the proof of Proposition 8 in Goyal and Joshi (2006). (ii) We demonstrate that without GATT two countries gain by forming a trade agreement. Consider any symmetric trading system $\mathcal{L}$ with $\eta_{i}(\mathcal{L})=\eta_{j}(\mathcal{L})$ $\forall i, j \in N$ where the agreement $L=\{i, j\} \notin \mathcal{L}$. The change in consumer surplus is:

$$
4(\alpha-c)^{2} \frac{\eta_{i}(\mathcal{L})^{2}+11 \cdot \eta_{i}(\mathcal{L})+26}{\left(7+\eta_{i}(\mathcal{L})\right)^{2}\left(8+\eta_{i}(\mathcal{L})\right)^{2}} .
$$

The profit of $i$ 's firm generated in $i$ is given by:

$$
\begin{aligned}
& \left(\frac{(\alpha-c)+\left(\eta_{i}(\mathcal{L})\right) \cdot\left(\frac{3(\alpha-c)}{7+\left(\eta_{i}(\mathcal{L})+1\right)}\right)}{\left(\eta_{i}(\mathcal{L})+2\right)}\right)^{2}-\left(\frac{(\alpha-c)+\left(\eta_{i}(\mathcal{L})-1\right) \cdot\left(\frac{3(\alpha-c)}{7+\eta_{i}(\mathcal{L})}\right)}{\left(\eta_{i}(\mathcal{L})+1\right)}\right)^{2} \\
= & -16(\alpha-c)^{2} \frac{15+2 \eta_{i}(\mathcal{L})}{\left(7+\eta_{i}(\mathcal{L})\right)^{2}\left(8+\eta_{i}(\mathcal{L})\right)^{2}}
\end{aligned}
$$


The sum of $i$ 's firm's profit in $j$ plus the change in tariff revenue is given by:

$$
\begin{aligned}
& \left(\frac{(\alpha-c)-2 \cdot\left(\frac{3(\alpha-c)}{7+\left(\eta_{j}(\mathcal{L})+1\right)}\right)}{\left(\eta_{j}(\mathcal{L})+2\right)}\right)^{2}+\left(\frac{(\alpha-c)-2 \cdot\left(\frac{3(\alpha-c)}{8+\eta_{i}(\mathcal{L})}\right)}{\left(\eta_{i}(\mathcal{L})+2\right)}\right) \cdot \frac{3(\alpha-c)}{7+\left(\eta_{i}(\mathcal{L})+1\right)} \cdot \eta_{i}(\mathcal{L}) \\
- & \left(\frac{(\alpha-c)-2 \cdot\left(\frac{3(\alpha-c)}{7+\eta_{i}(\mathcal{L})}\right)}{\left(\eta_{i}(\mathcal{L})+1\right)}\right) \cdot \frac{3(\alpha-c)}{7+\eta_{i}(\mathcal{L})} \cdot\left(\eta_{i}(\mathcal{L})-1\right) \\
= & \frac{(\alpha-c)^{2}}{\left(\eta_{j}(\mathcal{L})+8\right)^{2}}-3(\alpha-c)^{2} \frac{\eta_{i}(\mathcal{L})^{2}-\eta_{i}(\mathcal{L})-64}{\left(\eta_{i}(\mathcal{L})+7\right)^{2}\left(\eta_{i}(\mathcal{L})+8\right)^{2}} .
\end{aligned}
$$

From $(7),(8)$ and $(9)$, we conclude that $Y_{i}(t(\mathcal{L} \cup\{\{i, j\}\}), \mathcal{L} \cup\{\{i, j\}\})-Y_{i}(t(\mathcal{L}), \mathcal{L})=$ $(\alpha-c)^{2} \frac{\eta_{i}(\mathcal{L})^{2}+15 \eta_{i}(\mathcal{L})+\eta_{j}(\mathcal{L})^{2}+16 \eta_{i}(\mathcal{L})+120}{\left(8+\eta_{j}(\mathcal{L})\right)^{2}\left(7+\eta_{i}(\mathcal{L})\right)\left(8+\eta_{i}(\mathcal{L})\right)}>0$. Hence, $i$ and $j$ will deviate. Under endogenous tariffs, a multilateral agreement is necessary for the stability of the trading system.

\section{References}

Bagwell, K., and Staiger, R.W. (1998), Will Preferential Agreements Undermine the Multilateral Trading System?, Economic Journal, 108, 449, 1162-1182.

Bagwell, K., and Staiger, R.W. (1999a), An Economic Theory of GATT, American Economic Review, 89, 1, 215-248.

Bagwell, K., and Staiger, R.W. (1999b), Regionalism and Multilateral Tariff Cooperation, in J. Piggott and A. Woodland, eds., International Trade Policy and the Pacific Rim, Macmillan, London, 157-185.

Baldwin, R. (2006), Multilateralising Regionalism: Spaghetti Bowls as Building Blocs on the Path to Global Free Trade, World Economy, 29, 11, 1451-1518.

Bhagwati, J. (1993), Regionalism and Multilateralism: An Overview, in J. De Melo and A. Panagariya, eds., New Dimensions in Regional Integration, Cambridge University Press, Cambridge, 25-51.

Bhagwati, J., and Panagariya, A. (1996), The Theory of Preferential Trade Agreements: Historical Evolution and Current Trends, American Economic Review Papers and Proceedings, $86,2,82-87$.

Brander, J., and Krugman, P. (1983), A "Reciprocal Dumping" Model of International Trade, Journal of International Economics, 15, 3-4, 313-321.

Deardorff, A. V., and Stern, R. M. (1997), Multilateral Trade Negotiations and Preferential Trading Agreements, in A. V. Deardorff and R. M. Stern, eds., Analytical and Negotiating Issues in the Global Trading System, University of Michigan Press, Ann Arbor, $27-85$.

Durieu, J., Haller, H., and Solal, P. (2005), Interaction on Hypergraphs, Mimeo, Special Research Area 504 Publications 05-34, University of Mannheim.

Freund, C. (2000), Multilateralism and the Endogenous Formation of Preferential Trade Agreements, Journal of International Economics, 52, 359-376.

Furusawa, T., and Konishi, H. (2007), Free Trade Networks, Journal of International Economics, 72, 310-335. 
Goyal, S., and Joshi, S. (2006), Bilateralism and Free Trade, International Economic Review, 47, 3, 749-778.

Grossman, G.M., and Helpman, E. (1995), The Politics of Free Trade Agreements, American Economic Review, 85, 4, 667-690.

Jackson, M.O., and Wolinsky, A. (1996), A Strategic Model of Social and Economic Networks, Journal of Economic Theory, 71, 44-74.

Karacaovali, B., and Limão, N. (2008), The Clash of Liberalizations: Preferential vs. Multilateral Trade Liberalization in the European Union, Journal of International Economics, 74, 299-327.

Krishna, P. (1998), Regionalism and Multilateralism: A Political Economy Approach, Quarterly Journal of Economics, 113, 1, 227-251.

Mueller-Langer, F. (2012), Parallel Trade and its Ambiguous Effects on Global Welfare, Review of International Economics, 20, 1, 177-185.

Mrázová, M., Vines, D., Zissimos, B. (2013), Is the GATT/WTO's Article XXIV Bad?, Journal of International Economics, 89, 216-232.

Ornelas, E. (2005), Endogenous Free Trade Agreements and the Multilateral Trading System, Journal of International Economics, 67, 471-497.

Panagariya, A. (2000), Preferential Trade Liberalization: The Traditional Theory and New Developments, Journal of Economic Literature, 38, 2, 287-331.

Saggi, K., and Yildiz, H.M. (2010), Bilateralism, Multilateralism, and the Quest for Global Free Trade, Journal of International Economics, 81, 1, 26-37.

Saggi, K., and Yildiz, H.M. (2011), Bilateral Trade Agreements and the Feasibility of Multilateral Free Trade, Review of International Economics, 19, 2, 356-373.

van den Nouweland, A., Borm, P., and Tijs, S. (1992), Allocation Rules for Hypergraph Communication Situations, International Journal of Game Theory, 20, 255-268.

World Trade Organization (2011), World Trade Report 2011, The WTO and Preferential Trade Agreements: From Co-Existence to Coherence, WTO, Geneva. 